July 10, 2014

\title{
Interactive Online
}

\section{Learning on Campus:}

ITHAKA S+R

\section{Testing M00Cs and Other Platforms in Hybrid Formats in the University System of Maryland}

Rebecca Griffiths Matthew Chingos Christine Mulhern Richard Spies

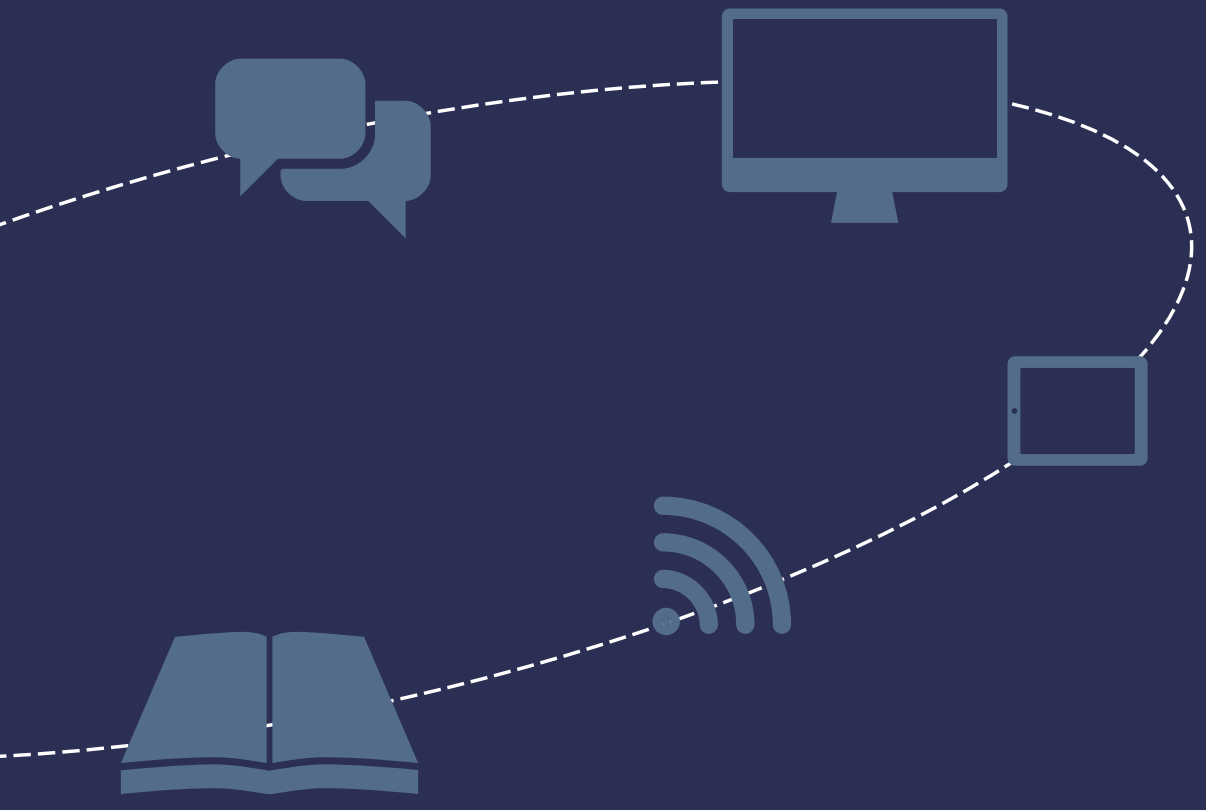




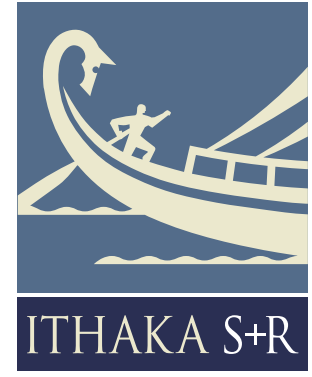

Ithaka $\mathrm{S}+\mathrm{R}$ is a strategic consulting and research service provided by ITHAKA, a not-for-profit organization dedicated to helping the academic community use digital technologies to preserve the scholarly record and to advance research and teaching in sustainable ways. Ithaka $S+R$ focuses on the transformation of scholarship and teaching in an online environment, with the goal of identifying the critical issues facing our community and acting as a catalyst for change. JSTOR, a research and learning platform, and Portico, a digital preservation service, are also part of ITHAKA.

Copyright 2014 ITHAKA. This work is licensed under a Creative Commons Attribution-NonCommercial 4.o International License. To view a copy of the license, please see http://creativecommons.org/licenses/by-nc/4.o/.

ITHAKA is interested in disseminating this report as widely as possible. Please contact us with any questions about using the report: research@ithaka.org. 


\section{Table of Contents}

2 Acknowledgements

4 Executive Summary

7 Introduction

10 Research Process

12 Findings

23 Lessons Learned

29 Summary

32 Appendix A: More Detail on Side-by-Side Tests

43 Appendix B: More Detail on Case Studies

47 Appendix C: More Detail on Cost Analysis

50 Appendix D: Descriptions of Case Studies

59 Appendix E: Study Instruments 


\section{Acknowledgements}

This study would not have been possible without the support and cooperation of many individuals and institutions who shared our desire to learn about the implications of using these emerging technologies in campus settings. First, we would like to acknowledge our partners at the University System of Maryland. MJ Bishop's contributions throughout the project were invaluable, and Jennifer Frank, Don Spicer, Nancy Shapiro and Lynn Harbinson were instrumental in helping to coordinate with faculty and staff at each institution. The leadership of Chancellor William "Brit" Kirwan and Senior Vice Chancellor for Academic Affairs Joann Boughman was crucial to gaining administrative and faculty support. Graduate Assistants Harish Vaidyanathan and Elizabeth Tobey helped to navigate technical problems and assemble diverse sets of data. Our faculty partners across the system inspired us with their courage in trying new teaching approaches under a spotlight and willingness to adapt in the face of numerous challenges. These include: Megan Bradley, Shoshana Brassfield, Ron Gutberlet, Amy Hagenrater-Gooding, Veera Holdai, Wanda Jester, Adrian Krishnasamy, Courtney Lamar, Velma Latson, Gina Lewis, Theresa Manns, John McMullen, Robert Moore III, Pamela O’Brien, John O’Rorke, Joseph Pitula, Allissa Richardson, Richard Seigel, Michael Shochet, Tatyana Sorokina, Daryl Stone, Sarah Texel, Johnny Turtle, Barbara Wainwright, Larry Wimmers, Marguerite Weber, and Wendy Xu.

Also essential was the collaboration with Coursera, which agreed to participate in this project at an early stage of its existence, and its institutional partners. We are especially grateful to Daphne Koller and Connor Diemand-Yauman for their support. The faculty and administrators at partner institutions who gave us permission to use their newly hatched MOOCs in our study deserve special attention. These include: Walter Sinnott-Armstrong and Ram Neta (Duke University), Celine Caquineau and Mayank Dutia (University of Edinburgh), Sarah Eichhorn and Rachel Lehman (University of California Irvine), Al Filreis (University of Pennsylvania), Jeffrey Borland (University of Melbourne), Mohamed Noor (Duke University), Jamie Pope (Vanderbilt University), Scott Rixner and Joe Warren (Rice University), Jeffrey Rosenthal and Alison Gibbs (University of Toronto), Peter Struck (University of Pennsylvania), Andrew Szegedy-Maszak (Wesleyan University), Karl T. Ulrich (University of Pennsylvania), Walter Sinnott-Armstrong and Ram Neta (Duke University), Celine Caquineau and Mayank Dutia (University of Edinburgh), Sarah Eichhorn and Rachel Lehman (University of California Irvine), Al Filreis (University of Pennsylvania), Jeffrey Borland (University of Melbourne), Mohamed Noor (Duke University), Jamie Pope (Vanderbilt University), Scott Rixner and Joe Warren (Rice University), Jeffrey Rosenthal and Alison Gibbs (University of 
Toronto), Peter Struck (University of Pennsylvania), Andrew Szegedy-Maszak (Wesleyan University), Karl T. Ulrich (University of Pennsylvania), and Dave Ward, Duncan Pritchard, Suilin Lavelle, Matthew Chrisman, Allan Hazlett, Michela Massimi, Alasdair Richmond (University of Edinburgh).

We are also indebted to the staff of the Open Learning Initiative, including Candice Thille and Norman Bier, who worked with faculty at Towson University and Salisbury University to set up the biology course despite the organizational change that occurred midway through the project.

This work would not have been possible without generous funding from the Bill and Melinda Gates Foundation and the flexibility we were given to guide the project in a rapidly changing external environment.

Finally, we are grateful to Ithaka $S+R$ 's senior advisors who helped to shape this effort, including Lawrence S. Bacow, William G. Bowen, Kevin Guthrie, and Deanna Marcum. 


\section{Executive Summary}

Online learning technologies show promise for educating more people in innovative ways that can lower costs for universities and colleges. This study represents the latest of Ithaka S+R's efforts to examine the "what" and the "how" of adopting these technologies in universities and colleges - what impact does their use have on learning outcomes and costs of delivering undergraduate instruction, and, if these technologies are shown to be effective, how can their use be accelerated and scaled up across institutions in strategic ways? A key objective of this study was to learn how faculty can take advantage of existing online content-sometimes created by professors at other institutions-to redesign their courses and benefit their students, and whether efficiencies can be created in this process.

Ithaka $\mathrm{S}+\mathrm{R}$ collaborated with the University System of Maryland to test the use of interactive online learning platforms in seventeen courses across seven universities. Fourteen of these tests used Massively Open Online Courses (MOOCs) on the Coursera platform, almost all embedded in hybrid course formats, and three used courses from the Open Learning Initiative at Carnegie Mellon University (OLI). We conducted seven side-by-side comparisons to evaluate outcomes of students in hybrid sections with those of students in traditionally taught courses, controlling for student background characteristics. In addition, we conducted ten case studies using MOOCs in smaller courses using a range of approaches. For all tests we collected detailed data on the time it took for local instructors to plan and deliver their courses. We also documented the implementation process in order to share what we learned about opportunities and challenges associated with embedding existing content in campus environments.

Our findings add empirical weight to an emerging consensus that technology can be used to enhance productivity in higher education by reducing costs without compromising student outcomes. Students in the hybrid sections did as well or slightly better than students in the traditional sections in terms of pass rates and learning assessments, a finding that held across disciplines and subgroups of students. We found no evidence supporting the worry that disadvantaged or academically underprepared students were harmed by taking hybrid courses. These findings are significant given that instructors were teaching the redesigned courses and using new technology platforms for the first time, with, on average, just over half as much class time as traditionally taught sections.

The use of technology to redesign large introductory courses has the potential to reduce costs in the long run by reducing the time instructors spend planning and delivering courses. But, not surprisingly, we found that redesigning courses 
For adoption of online

technologies to grow at scale, providers will need to make

tools and content easier to implement and repurpose, and provide assurance of ongoing availability. to incorporate existing online content has significant start-up costs. The data we collected from instructors indicate that designing courses using MOOCs or OLI is a substantial undertaking, and can take approximately 150-175 hours, with wide variations between instructors. Offsetting these initial costs in the long run may well be possible over multiple iterations of efforts like those we have studied here.

Despite the similar student outcomes produced by the two course formats, students in the hybrid sections reported considerably lower satisfaction with their experience. Many indicated that they would prefer to have more face-to-face time with instructors. Although our findings showed promise, they also affirmed that online learning technologies alone, at least in their current form, are not a panacea for higher education's challenges. Students place high value on their personal experiences with faculty.

This collaboration with faculty from various disciplines on a diverse set of campuses also yielded a wealth of information about the implementation of online materials developed elsewhere in campus-based courses. The faculty participants generally had very positive experiences using MOOCs in their courses, despite the fact that many did not feel that those they used were a good fit. They cited a number of benefits, including exposure to excellent professors and different ways of teaching content, enriching class discussions, the ability to redesign classes without creating online content from scratch, and replacing textbooks with more engaging content. The great majority would like to teach with MOOCs again and would recommend these tools to their colleagues.

At the same time, participating faculty had to work through many types of implementation challenges, including fitting sometimes poorly matched content into their courses and technology integration problems. Many issues remain to be resolved with regard to intellectual property and how online resources will be sustained-a crucial question given the amount of time instructors spent redesigning courses with these materials. For adoption of online technologies to grow at scale, providers will need to make tools and content easier to implement and repurpose, and provide assurance of ongoing availability. Institutions that are investing heavily in the creation of MOOCs will need to determine that making these materials available and useful to other institutions is a priority. Models that do not allow customization by the faculty are unlikely to gain widespread adoption, at least in the near to medium term.

This project also provided insights into the process of innovation within institutions and public university systems. It was clear that administrative leadership was essential to stimulate faculty interest and ensure access to logistical support. At the same time, the decision of whether or not to participate in any kind of course redesign ultimately rests with the faculty. They are unlikely to embrace new technology-enhanced models on a large scale without adequate incentives and a belief that these efforts will garner professional rewards. Moreover, institutions cannot rely on individual innovators to make progress. Course redesigns must take place in connection with an overarching strategic framework in order to have significant impacts on overall student success and costs.

One faculty partner said that she participated in this project because she could see that change in higher education is inevitable, and she preferred to be part of the 
process of shaping the future rather than sit on the sidelines. Another said that he thought the MOOCs he used in his course were "brilliant" and "raised the overall level of the class." He commented that his colleagues would be more likely to take advantage of these resources without the MOOC label, which has become a distraction. Given the challenges faculty face with underprepared students, he said, they should take advantage of all available tools at their disposal. 


\section{Introduction}

The story is now well documented. The number of students in our country who need post-secondary degrees to compete in the global workforce is increasing. Concerns are growing that a majority of American students enter college with significant gaps in their math and literacy skills, and that too many students then either fail to graduate or do so without having obtained the skills and knowledge required by employers. The student population itself is changing, as the traditional notion of a college student as an 18-24 year old living on campus with at least some financial support from parents now accounts for a minority of students. ${ }^{1}$ At the public institutions that educate these students, tuition has risen dramatically due to a confluence of rising costs and falling state support, even as median family incomes are stagnating. ${ }^{2}$ At worst, it is a crisis. At best, it is a moment that demands innovation.

For the first time, a combination of technological and social factors may be aligning that could offer a new and more sustainable path forward. Online learning technologies hold out the promise that students might learn as effectively online as they do through traditional modes for substantially lower costs. As William "Brit" Kirwan, the chancellor of the University System of Maryland wrote recently, "If, as a nation, we have any hope of preventing the train wreck that [decreasing public funding and rising costs] portend, we need interventions like interactive learning online and we need them soon." At the same time, the intense public scrutiny and media attention focused on Massively Open Online Courses ("MOOCs") has changed the nature of the conversation about online learning among faculty, deans, administrators, and trustees. Even elite institutions are feeling compelled to experiment with these new technologies. The academy is increasingly receptive to the idea of moving forward carefully and deliberately with these new forms of instruction.

This is, therefore, a moment of great opportunity. But it is not without its challenges. The application of online learning technologies is very different for auditorium-style lectures versus intimate upper division seminars. Not all of the platforms being offered and developed in the marketplace are fit-for-purpose, especially for application by faculty teaching in colleges and universities. Even if the technology was perfect, transforming long-standing practices and processes,

1 Louis Soares, "Post-traditional Learners and the Transformation of Postsecondary Education: A Manifesto for College Leaders," American Council on Education, January 2013, 6.

2 See Michelle Jamrisko and Ilan Kolet, "College Costs Surge 500\% in U.S. Since 1985: Chart of the Day," Bloomberg, Aug 26, 2013, and Jordan Weissmann, "The 38 States That Have Slashed Higher Education Spending," The Atlantic Monthly, January 23, 2014. 
many of which have served institutions very well for a long time, is difficult. There is understandable resistance to change, especially without very strong evidence to show that the outcomes are going to be an improvement over traditional practices. Many instructors are experimenting with new approaches (more than policymakers may realize), but it is not clear whether incremental course-level policy makers are adding up to meaningful change for entire schools and institutions.

For the leadership of a higher education institution, this moment of opportunity and challenge raises two kinds of questions: what to do, and how to do it. The "what" refers to the pedagogical and technological choices that must be made to incorporate online learning technologies into the education provided to students. Factoring in the costs of providing this education is crucial. The "how" encompasses the steps leaders must take to overcome organizational and cultural resistance to change.

The Ithaka S+R study, Interactive Learning Online in Public Universities (hereafter referred to as "ILOPU") signified an important step forward in addressing the "what" with a large scale test of an interactive online learning platform employing randomized control trials, thus addressing some of the methodological flaws characterizing much earlier research. ${ }^{3}$ But as Deanna Marcum wrote in the preface to that study, "More research is needed. Even though the analysis was rigorous, it was a single course. We need to learn more about the adaptability of existing platforms for offering other courses in different environments."

Also in 2012, a team of Ithaka $S+R$ researchers conducted a study entitled Barriers to Adoption of Online Learning Systems in U.S. Higher Education,,$^{4}$ examining the landscape of important developments in online learning, the benefits that colleges and universities hope to achieve with these technologies, and the obstacles they face. In other words, this study explored the "how" of accelerating implementation of online learning technologies to address the challenges facing higher education.

Ithaka S+R partnered with the University System of Maryland (USM) to build upon these two studies and to shed more light upon both the questions of "what" and "how." Maryland served as a test bed for various technology platforms in a variety of subject areas on different campuses, while Ithaka $\mathrm{S}+\mathrm{R}$ monitored, assessed, and documented lessons learned from these implementations. We hope that rigorous assessment of how students fared will help reassure those concerned about educational quality, while the documentation of obstacles encountered and overcome will help those struggling with implementation.

3 William G. Bowen, Matthew M. Chingos, Kelly A. Lack, Thomas I. Nygren, Interactive Learning Online in Public Universities: Evidence from Randomized Trials, Ithaka S+R, May 22, 2012. The ILOPU study was evaluated by What Works Clearinghouse and determined to meet the WWC group design research standards without reservation. The WWC report is available at http://ies.ed.gov/ncee/wwc/ SingleStudy Review. aspx? sid $=20088$.

4 Lawrence S. Bacow, William G. Bowen, Kevin M. Guthrie, Kelly A. Lack, Matthew P. Long, Barriers to Adoption of Online Learning Systems in U.S. Higher Education, Ithaka S+R, May 1, 2012. Available at http://www.sr.ithaka.org/research-publications/ barriers-adoption-online-learning-systems-us-higher-education. 
We learned an enormous amount in the process of trying to answer the questions we posed, which were:

- How can a primarily direct-to-student MOOC platform be used by institutions to teach students enrolled in traditional degree programs?

Can MOOCs be used to create hybrid or primarily online courses for credit? Can they enable instructors to teach large classes more effectively? What level of customization is needed, and how is this best achieved? What issues arise around intellectual property, use and sharing of student data, and other sensitive areas?

- What are the learning outcomes from hybrid courses using externally developed online content compared to face-to-face instruction?

What are the best ways to test these outcomes? Do any particular subgroups of students seem especially helped or harmed by use of these materials? What supports and interventions are needed to promote student success?

- What are the strengths and weaknesses of emerging platforms? How do MOOCs compare to each other and to adaptive learning platforms provided by publishers and start-up ventures? What advantages and disadvantages does each of these offer institutions, faculty, and students?

- What kinds of cost savings are possible through implementation of these technologies? How should we track upfront and recurring costs?

What costs can be saved in individual courses, and what are the implications of implementing online learning platforms across many introductory courses for the institution as a whole?

- What can be learned through this process and from USM's rich experience in implementing new instructional models? What are the key elements of an institutional and system-wide strategy for online learning? How can new methods of course delivery using online platforms be institutionalized and sustained? What incentive systems are appropriate to motivate faculty support and participation? What can we learn about effecting change in a public system through this process?

The Research Process section will provide a brief description of the activities undertaken in this study. This is followed by a Findings section, which reports our quantitative and qualitative results, as well as our findings on costs. Next we return to the questions posed above and share our Lessons Learned on these topics based on these findings. For those interested in understanding our methodology and results in more details, these are described at length in the appendices, along with various data collection instruments. 


\section{Research Process}

The proposal for this project called for side-by-side comparison tests, but we quickly determined that we would need a more nuanced approach to gain insights into a broad range of issues. We implemented five pilots (by which we mean small scale tests used to refine our research methods and/or work through implementation issues), ${ }^{5}$ eight side-by-side comparison tests, and ten case studies, each of which is a campus-based course using MOOC content in a variety of ways. We do not report on the pilots or one of the side-by-side tests, reducing our sample to seven side-by-side comparisons and ten case studies. ${ }^{6}$ The process of selecting courses to include was extensive and influenced by many factors, including the availability of MOOCs in particular fields and our ability to gain permission to use them, the interests of faculty in USM institutions, and the support of their departments. A diverse set of institutions participated in the study, including research universities, metropolitan institutions, regional comprehensives, and HBCUs. ${ }^{7}$

The side-by-side tests were conducted in large, introductory courses to compare hybrid sections using either MOOCs supported by Coursera or materials from the Open Learning Initiative (OLI) developed at Carnegie Mellon University with traditionally taught sections. In five of the seven tests, hybrid sections had reduced face-to-face class time, while in two the online materials were purely supplementary. All of these courses had multiple sections, and some had different instructors across the sections. The courses covered computer science, biology, communications, statistics and precalculus. Detailed information about the individual tests is provided in Appendix A.

The case studies were set up to explore a diverse set of strategies for using MOOCs in campus-based courses and to document the instructor and student experiences in these courses. We selected proposals in which faculty members had clear ideas of what they hoped to accomplish or what problems they aimed to solve with the use of the

5 One of these pilots was a precursor to a larger test that took place during the fall; the second pilot had the option to repeat the test but the professor opted instead to develop home-grown materials for the next iteration of his hybrid course. Three pilots used an online developmental math program from Pearson, examining student outcomes in sections in which traditional teaching methods were replaced by technology-enhanced instruction.

6 The MOOC creator for one of the side-by-side tests requested late in the summer that his materials not be used. The professors for this course continued with the plan to redesign their course but they used static publisher materials instead. In addition, we were unable to receive student outcome data from their test and thus unable to include it in our analyses. For one of the seven side-by-side tests, the post-tests are excluded from the analysis because the instructors were unable to agree upon a common post-test.

7 This process is described in detail in an interim report, available at http://www.sr.ithaka.org/sites/ default/files/reports/S-R_Moocs_InterimReport_20131024.pdf. See pages 7-8. 
online materials. Nine of these courses were hybrid, and one was entirely online. The case studies enabled us to gain additional insights into the potential opportunities of using online content in different (often very creative) ways and the implementation challenges associated with these approaches.

We wished to engage with multiple types of technology platforms that offer high quality, interactive online course content. Those selected had different types of appeal: MOOC platforms have stimulated creation of a large quantity of valuable online content in a short period of time, had high levels of awareness among faculty at the time we initiated the study, and could be an important vehicle for institutions to share online course content with one another; the OLI courses offered an opportunity to test an adaptive learning platform that has been used by a good number of institutions, and three groups of faculty wanted to use their courses; and commercial publishers such as Pearson have invested heavily in the development of widely-used digital products for instruction in quantitative subjects. (Tests using Pearson are still underway and will be reported at a later time.) We wished to work with multiple MOOC platforms, but were only able to secure agreements with Coursera and its partners when the test cases were being assembled.

In the side-by-side tests, which are the basis for our quantitative findings, we collected administrative data in order to control for student characteristics such as academic preparation and demographic characteristics. Outcome measures included pass rates, scores on common post-tests or final exams, and grades. For all tests we conducted surveys of students to gather additional background information and to understand their experiences with the online technologies. We conducted interviews with instructors during the planning stages and at the conclusion of the tests.

We also collected time use data from instructors and support staff in order to analyze the impact on costs. Detailed descriptions of the methodologies used, protocols, individual course descriptions, and data collection instruments are provided in Appendices A through E.

It is challenging under any circumstances to conduct educational experiments, and in this case our task was further complicated by the fact that MOOCs were new and designed for a different purpose. Some of our faculty partners selected MOOCs for their courses before they had even been completed! At the same time, the environment is changing very quickly, and there is an argument for striving to be nimble in our approach to testing new models and technologies. We aimed to strike a balance among our at-times conflicting goals_ — conducting experiments with sufficient rigor to yield meaningful outcomes, avoiding imposition of excessive risks on students (or faculty), and producing results in a timely enough fashion to be relevant and useful. 


\section{Findings}

\section{Quantitative Findings}

This section reports findings from our quantitative analysis of side-by-side comparison tests, which is quasi-experimental in that we attempted to approximate an experimental design by identifying comparison groups that were similar to the treatment groups in important respects. In order to build upon lessons from the ILOPU study, which employed a randomized design, we modified our methodological approach in order to test more technology platforms in more types of courses. We report results from seven side-by-side tests comparing hybrid sections using MOOCs and OLI with traditionally taught sections. Courses included math, statistics, biology, computer science, and communications. These tests involved 1,598 students with diverse backgrounds at three institutions.

Table 1. Summary Statistics for Side-by-Side Comparison Tests

\begin{tabular}{lll} 
& Trad. (N=820) & Hybrid $(\mathbf{N}=\mathbf{7 7 8})$ \\
\hline SAT Math & 511 & 514 \\
\hline SAT Verbal & 511 & 510 \\
\hline Cum GPA & 2.82 & 2.85 \\
\hline Race/Ethnicity & & \\
White & $50 \%$ & $51 \%$ \\
\hline Black & $31 \%$ & $34 \%$ \\
\hline Hispanic & $4 \%$ & $4 \%$ \\
\hline Asian & $5 \%$ & $4 \%$ \\
\hline Other/missing & $9 \%$ & $7 \%$ \\
\hline Female & $61 \%$ & $60 \%$ \\
\hline
\end{tabular}

Parents' Income

\begin{tabular}{lll} 
Less than $\$ 50,000$ & $15 \%$ & $17 \%$ \\
\hline$\$ 50,000-\$ 100,000$ & $20 \%$ & $21 \%$ \\
\hline More than $\$ 100,000$ & $37 \%$ & $33 \%$ \\
\hline Missing & $28 \%$ & $29 \%$ \\
\hline Age & 20.0 & 19.8
\end{tabular}

Our findings indicate that students in hybrid sections fared as well or slightly better than students in traditional sections in terms of pass rates, scores on common assessments (a final exam or post-test administered as part of the study), 
and grades (Figure 1). ${ }^{8}$ In the case of the final assessment scores (but not pass rates), the difference between traditional and hybrid sections is statistically significant at the 10 percent level. In other words, we can be fairly confident that this positive difference favoring the hybrid sections did not arise by chance. This result seems more significant when one considers that instructors were teaching with these materials in new formats for the first time.

Those using OLI's biology course had slightly positive outcomes, and differences for those using various MOOCs were statistically indistinguishable from zero (see Appendix Table 5). However these effects are not statistically distinguishable from each other. Additionally, the difference in estimates could result from a range of factors, including both the platform and the subject matter (the OLI courses were all biology courses and none of the MOOC courses were in biology). Consequently, we focus on results that combine all of the side-by-side tests, which better address our more general research question regarding the effects of using different technologies to redesign traditional courses.

These findings of small positive or zero effects of taking the hybrid version of a course held true for all important subgroups we examined, including those from low-income families, under-represented minorities, first-generation college students, and those with weaker academic preparation. Appendix Table 4 shows these results. We think it is important to emphasize that we found no consistent evidence of negative effects of the hybrid format for any of these subgroups.

Figure 1. Student Outcomes in Traditional and Hybrid Sections

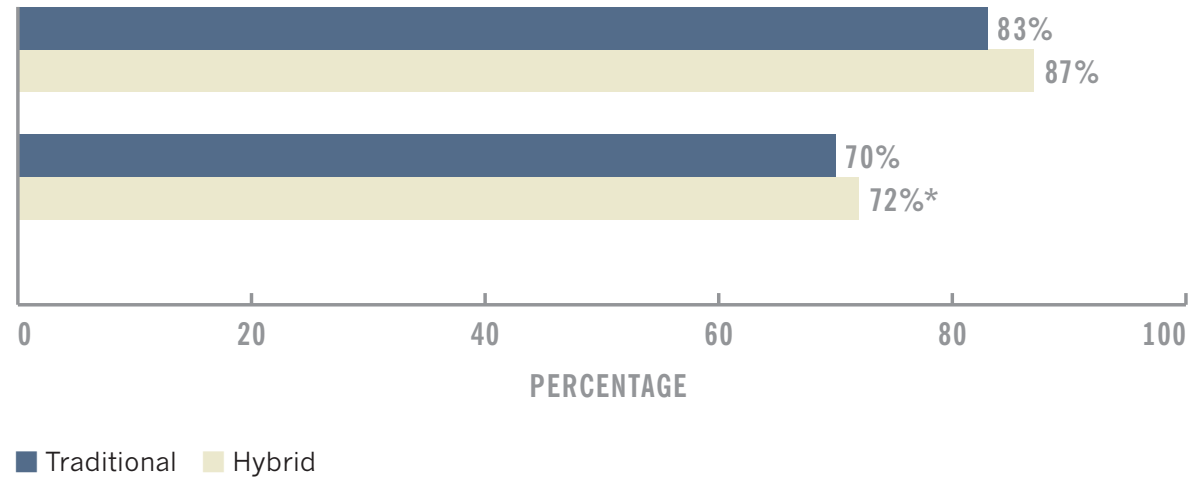

Notes: * $p<.10$; results only include controls for each course. Detailed outcomes results are available in Appendix Table 1.

How confident should we be that these results are reliable? We readily acknowledge shortcomings in our methodology and will examine these in some detail. First, we did not attempt random assignment of students to different sections, creating the potential for selection bias. An examination of student characteristics in the traditional and hybrid sections, reported in Table 1 , indicates that there were no substantial differences between the groups, at least none that are detectable

8 The results in Figure 1 adjust for course-specific differences in performance. In other words, they show a weighted average of within-course differences between the hybrid and traditional sections across all seven tests. The raw data are roughly similar, with pass rates of 83 and 86 percent in the traditional and hybrid sections, respectively, and final assessment scores of 70 and 74 percent. 
in observable data such as age, race/ethnicity, gender, family income, or SAT/ACT scores. These data suggest that students' decisions about whether to take a course in a hybrid format bore little relation to their academic preparation and personal backgrounds. It is possible (even likely) that these decisions hinged more on factors such as scheduling than on the format of the course, and we note that in four of the courses students did not know whether they were signing up for a hybrid or traditional version. It is also worth noting that two of the courses (biology $\mathrm{C}$ and statistics) had equal amounts of face-to-face time in the traditional and hybrid sections.

It is certainly possible that traditional- and hybrid-format students differed in their unmeasured traits, such as motivation or perseverance, which are not captured by the characteristics we observed. However, the similarity of the two groups at baseline and the fact that including control variables in the analysis makes little difference gives us about as much confidence in the results as is possible in the absence of random assignment. ${ }^{9}$ Furthermore, while individual tests have minor positive or negative results, we do not see dramatic differences between the seven tests, and the distribution of student outcomes within the hybrid and control sections are similar (see Appendix Table 3).

Second, we did not randomly assign instructors to different sections, and in four of the seven courses, traditional and hybrid sections were taught by different instructors. It is therefore possible that instructors who taught the hybrid sections in that subset of tests always achieve better (or worse) learning outcomes than their colleagues. To examine variation among instructors, we collected background information to determine whether instructors teaching traditional sections had different characteristics from those teaching hybrid sections. The only notable difference was that students in traditional sections were more likely to have instructors with experience teaching with technology (Table 2). As shown in Appendix Table 5, when we control for instructor characteristics, we see a modest positive impact on post-test scores, while the hybrid effect on pass rates and grades is not statistically different from zero. It is also worth noting that of the four courses with different instructors, three were developed and taught by teams, and one was developed by a course coordinator who did not teach any of the sections.

Table 2. Summary Statistics

\begin{tabular}{lll} 
& Trad. $(\mathbf{N}=\mathbf{8 2 0})$ & Hybrid $(\mathbf{N}=\mathbf{7 7 8})$ \\
\hline Weekly F2F minutes & 126 & 72 \\
\hline Section size & 76 & 77 \\
\hline Instructor Characteristics & & $54 \%$ \\
\hline Tenure-track & $52 \%$ & $100 \%$ \\
\hline Full-time & $91 \%$ & $55 \%$ \\
\hline Taught with tech before & $81 \%$ & 13.5 \\
\hline Years teaching experience & 14.5 & 13.4 \\
\hline Total times taught course & 18.7 & 7.7
\end{tabular}

9 In other words, when we control for SAT scores, cumulative GPA at the beginning of the semester, race/ ethnicity, gender, parents' income, and age, estimates of the effect on pass rates change from 3.6 to 3.0 percentage points, and the estimate for the post-test/final is unchanged at 2.4 percentage points. 
Finally, there were significant variations in the formats and local conditions for each course. For each test we relied upon the instructors' assessment instruments (as opposed to nationally recognized exams) to evaluate student outcomes. This decision was in keeping with the general spirit of this study - that our faculty partners were the primary arbiters of what students needed to learn to succeed in their courses and programs. The research team focused on ensuring that assessments were applied consistently across sections and evaluated objectively.

Taking these considerations into account, we see good reason to be confident of these results. Thus, we believe they can add further weight to an emerging consensus that online technology can be used to deliver hybrid courses with reduced class time without compromising student outcomes. ${ }^{10}$ Moreover, these results run counter to concerns that online learning technologies harm certain subgroups of students, at least when used in hybrid formats (as opposed to entirely online formats, in which there is some evidence that academically at-risk students fare worse).${ }^{11}$ And they suggest that the findings from the ILOPU study and other recent research may apply to a range of subjects.

On the other hand, students in these tests gave the hybrid sections considerably lower satisfaction ratings. Overall they enjoyed the courses less and felt that they had learned less than their peers in face-to-face sections. In response to a free text question asking what could be improved about the courses, around ten percent of students remarked that they wished they had more class time with their professors. This finding is also consistent with the ILOPU study and Joyce, Crockett, Jaeger, Altindag and O'Connell study, which suggested that students on average enjoy hybrid courses less. ${ }^{12}$

Figure 2. Student Evaluations of Traditional and Hybrid Sections

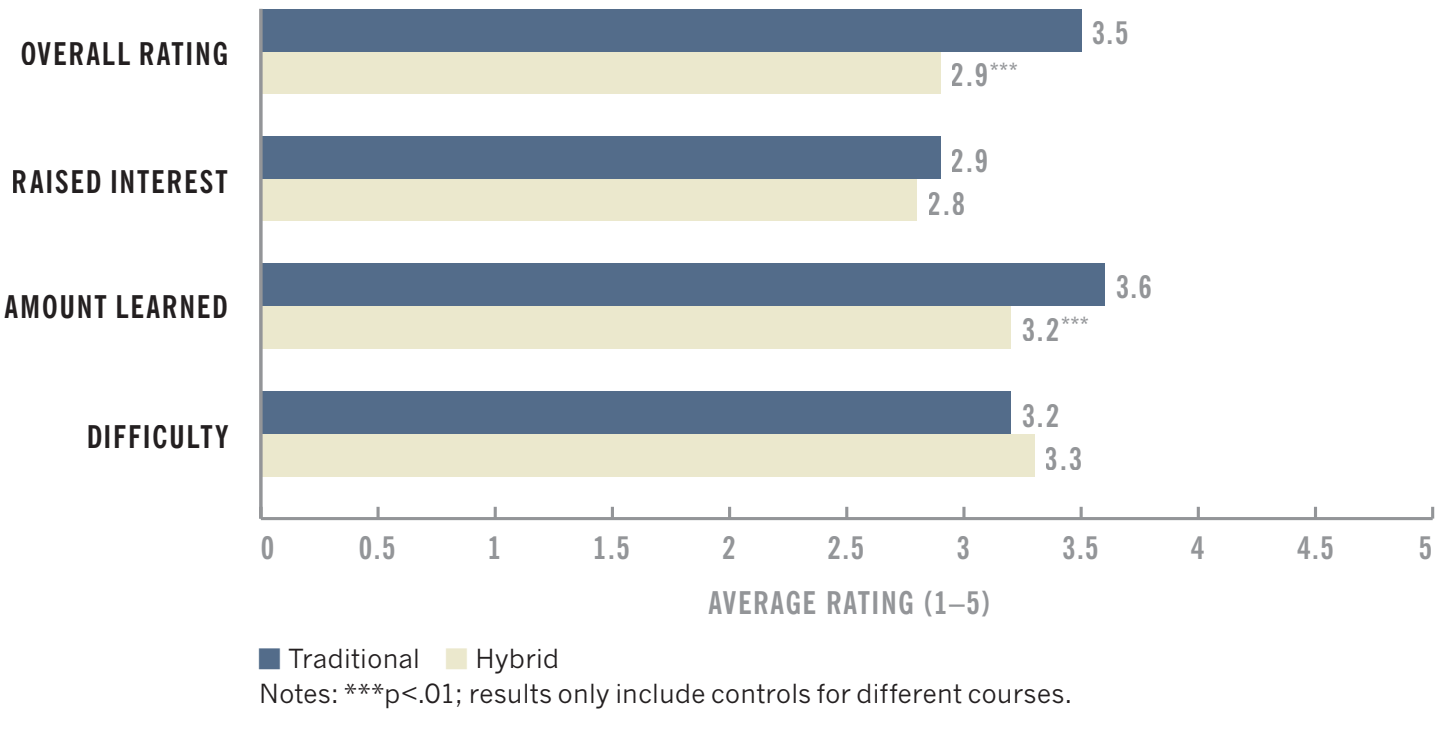

10 Theodore Joyce, Sean Crockett, David A. Jaeger, Onur Altindag, Stephen D. O'Connell, "Does Classroom Time Matter? A Randomized Field Experiment of Hybrid and Traditional Lecture Formats in Economics," NBER Working Paper Series, March 2014. See also Bowen et al, Interactive Learning at Public Universities: Evidence from Randomized Trials.

11 Di Xu and Shanna Smith Jaggars, "Adaptability to Online Learning: Differences Across Types of Students and Academic Subject Areas," CCRC Working Paper, February 2013. http://ccrc.tc.columbia. edu/media/k2/attachments/adaptability-to-online-learning.pdf. See also Johnson, Hans and Marison Cuellar Mejia. "Online Learning and Student Outcomes in Community Colleges," Public Policy Institute of California, May 2014, accessed June 16, 2014, http://www.ppic.org/main/publication.asp?i=1096.

12 Joyce et al, Bowen et al. Interactive Online Learning on Campus 
We were interested to see whether there were differences in student attitudes among subgroups, such as first year vs. non-first year students. These data suggest that students who might be considered academically at-risk had the same or, if anything, less negative attitudes toward the hybrid formats than their peers. In other words, students who were not first-year, whose parents have college degrees, who had higher than average SAT scores, and who are not under-represented minorities tended to give hybrid sections lower ratings. These students also appear to spend more hours on course work outside of class time than at-risk subgroups. These data are reported in Appendix Table 7.

\section{Qualitative Findings}

This section describes qualitative findings from both side-by-side tests and case studies, which together provided seventeen instances for observation. These findings pertain to the implementation process of embedding existing online content in campus-based courses, the experience of instructors teaching these courses, and observations from student surveys. Because most of the instances used MOOCs and these are relatively new and unfamiliar, this section reports primarily on courses using these materials.

Instructors used MOOCs to address a range of goals and problems in their courses. Several faculty members used MOOCs to strengthen students' foundational skills such as critical thinking and self-directed learning. For example, a studio arts instructor augmented a course on public installations with a MOOC on critical reasoning in order to teach students to approach art and evaluate information resources more analytically. Another used a MOOC on critical reasoning as the centerpiece of a three course "learning community" for first year students, whereby the online materials were used both for their content and as a vehicle to teach students how to "consume" the online materials. ${ }^{13}$ Another integrated a course on nutrition into a learning community aimed at improving students' personal health and fitness practices, which have been shown to correlate with student success.

Participants also attempted to use online platforms to enhance or replace other forms of instruction. Four professors used MOOCs to replace or supplement textbooks in their courses, with the expectation that online materials would be more engaging or accessible for students. Three teams of faculty used OLI for similar purposes. One instructor saw an opportunity to enhance an online course with video lectures, which she did not have time or resources to create herself. Another used a MOOC for an entire module of her course that was not her own area of expertise.

In pursuit of these goals, faculty members employed a range of strategies to incorporate MOOCs in their courses. All made substantial use of video lectures and most used online quizzes, though only for participation grades. Two assigned students to use the peer grading function. One had her students enroll in the public offering of the MOOC and participate in global discussion boards. None of the

13 Students met regularly with an undergraduate mentor to watch videos together and discuss how to take notes and how to determine what concepts were most important. 
instructors relied exclusively on the assessments in the MOOCs, as they did not believe that they tested adequately the particular skills and knowledge required for the local programs.

Figure 3: MOOC Components used by Faculty in their Courses

What components of the MOOC did you use in your course?

ENTIRE MOOC

MULTIPLE COMPONENTS (VIDEOS, QUIZZES, FORUMS)

VIDEOS ONLY

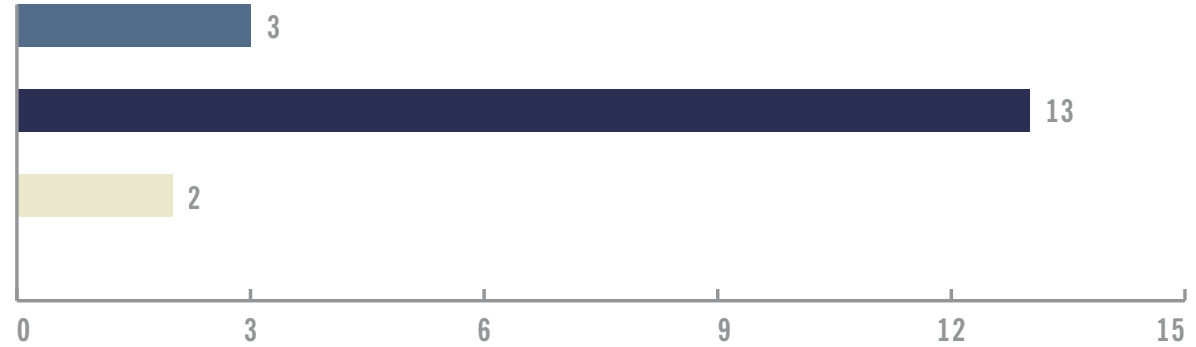

Note: some instructors taught different sections of the same course.

We were struck by how positively the faculty members who participated in this study described their experiences with MOOCs. They identified many types of benefits: some enjoyed viewing the MOOC lectures and observing how colleagues elsewhere teach their subjects, which one described as a form of professional development for teaching. Several enjoyed the flexibility to teach their courses in different ways, as the lecture videos freed them from covering content during class time and enabled them to engage in more active teaching practices. None said that using MOOCs made teaching less rewarding for them personally.

Faculty partners also observed a number of intangible benefits to students from using MOOCs. Several argued that exposure to high level intellectual discourse from different environments influenced students to adopt similar styles in their own class discussions and pushed them to make more analytical comments. Two who used MOOCs on critical reasoning found that students gained a stronger appreciation of the distinction between opinion and argumentation, and improved their abilities to substantiate arguments and critique sources. One stated that use of MOOCs did a "brilliant" job of communicating technical information in a much more engaging manner than textbooks and other supplementary materials upon which he had relied in past offerings of that course and "raised the overall level" of the class.

In all final interviews we asked instructors whether they would like to use MOOCs again in their teaching:

Figure 4:

Would you like to use a MOOC in your teaching again?

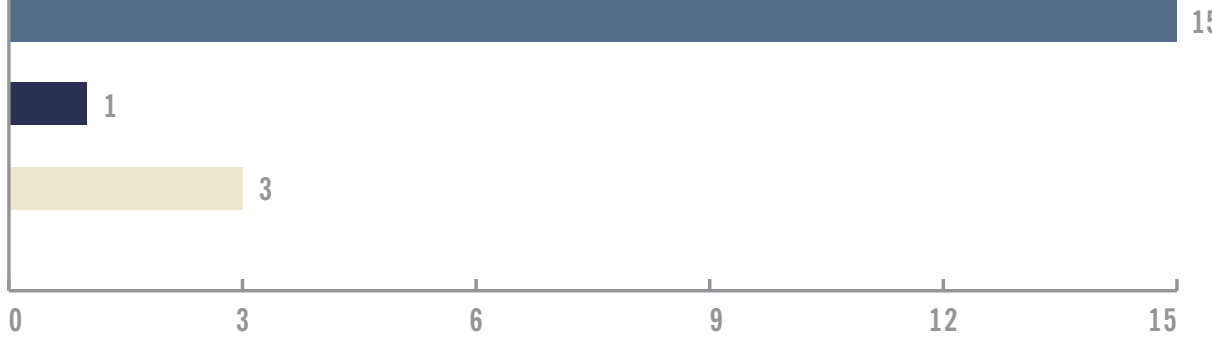


In fact, more than half of those that participated in this part of the study have said they would reuse the same MOOCs if given the option despite issues with fit. Thirteen respondents also said they would recommend to their colleagues that they try teaching with MOOCs.

One could interpret these responses as merely reflecting the fact that close to three quarters of these faculty members had volunteered to be part of the study and thus were predisposed to regard the experience as a success. We certainly cannot discount this possibility; however, it is notable that the majority of their accounts were so positive given all the concerns that have been raised about how MOOCs could impact faculty. Indeed, several remarked that their own fears about MOOCs replacing faculty were actually allayed by their experiments, as they became convinced that their students needed a faculty member to guide them through the MOOC, explain the parts they did not understand, and motivate them to continue. Five observed the need for a local instructor to provide a "bridge" to the online materials, which are not tailored to students' needs. One instructor argued that faculty fears are misplaced and that people would be more likely to see the value in MOOC materials without the "MOOC" label, which has become a distraction. Given the challenges faculty face with underprepared students, he said, they should take advantage of all available tools at their disposal.

These benefits seem to us quite compelling, but the implementation issues encountered in setting up and delivering these courses were daunting. Many of these issues arose because we were attempting to use the online courses for a purpose other than that for which they were designed. These fall in the categories of content fit, intellectual property, and technology.

\section{Content Fit}

Finding and adapting online content to use for a hybrid course posed the greatest challenge for faculty partners. MOOCs illustrate the priorities of their creators, and these are not necessarily the same priorities that other faculty have for their individual students. Moreover, academic departments develop degree program curricula as a whole, making deliberate decisions about when and where certain content should be taught and competencies assessed within specific courses. To integrate a MOOC into an existing class is not necessarily a simple case of choosing what pieces to include or exclude. Even with online course materials that are a fairly close fit with the pedagogical approach of the instructor and needs of the students, the local instructor may need to re-conceptualize or restructure his or her existing course to fit with the online content.

About a third of the faculty partners said that the MOOC assumed too high a level of prior knowledge or quantitative skills, while four thought that the assessments did not demand the level of rigor instructors would expect for courses in their institutions. We heard that MOOCs taught concepts in a different way or emphasized different topics than those preferred by the faculty partners. In one course, for example, the USM instructor found that the lecture videos presented topics in a different sequence than his syllabus, and moreover that they taught 
concepts in a cumulative fashion with frequent references to previous units, making it difficult for him to use them out of order. In general, we learned, the first generation of MOOCs were structured as coherent narratives, while professors using these materials prefer more flexible modules or "chapters."

Content fit was particularly important in introductory courses, which are integral to the curriculum and need to be well matched to the abilities of the student population and requirements of subsequent courses in those programs. Finding a MOOC that was a good fit with an existing course seemed fairly hit-or-miss, and even MOOCs that were reasonably well suited required some customization or "bridging." (The OLI course also required substantial augmentation to meet the needs of local instructors.) As a result of these challenges, seven faculty members concluded that they could create more appropriate online course materials for their students. All of the instructors participating in this study created their own assessments to go with the MOOCs.

Our observations in this study reaffirm previous findings that faculty must be able to customize the online materials for courses they teach — and for which they must certify that students have achieved the expected learning outcomes. ${ }^{14}$ When we recruited participants for the study, the ability to customize the online courses was a top priority, and it is quite possible that we would not have secured any partners without this capability.

\section{Intellectual Property}

While MOOCs are "open" in the sense of being free to students who enroll in public offerings, they have fairly restrictive terms for other kinds of use. ${ }^{15}$ One may not take these courses as part of any kind of tuition-based or creditbearing course without specific permission, nor is one allowed to modify or repurpose the content in any way. There is currently no standardized way to obtain these permissions.

A critical issue is how to balance the instructors' freedom to teach their courses as they wish with the desires of some MOOC creators to monitor or restrict the way their online content is used. The unique value of MOOC materials derives at least in part from their authorship by exceptional professors, and we detected understandable anxiety from several of those approached for this study about losing control of their intellectual creations. Two of these professors expressed concerns with the idea that their courses might be "canned" or repurposed by unknown faculty in other institutions. These worries were by no means universal, however; the majority of Coursera's partners whose permission we sought to include their courses in our study consented readily.

14 Bacow et al.

15 For example, Coursera's Terms of Use state: "You may not take any Online Course offered by Coursera or use any Statement of Accomplishment as part of any tuition-based or for-credit certification or program for any college, university, or other academic institution without the express written permission from Coursera." It also states "You may download material from the Sites only for your own personal, non-commercial use. You may not otherwise copy, reproduce, retransmit, distribute, publish, commercially exploit or otherwise transfer any material, nor may you modify or create derivatives works of the material." 
Questions arose for which there were no clear answers or precedents: when an instructor adapts a MOOC for use in a hybrid course, who owns and/or has rights to use the adapted version? What kinds of adaptations should be permitted? Does the instructor who adapted the MOOC have any assurance that these materials will be available for future use? If a new version of a particular MOOC is released, would the instructor be required to use the most recent version, even if this means making adaptations to her course all over again? These are critical questions in view of the extensive efforts required to redesign courses using the online materials. For this project we devised ad hoc solutions-and were very fortunate to have partners who were willing to participate despite considerable uncertainties as to how these issues would be resolved. It is clear, though, that more standardized policies are necessary to enable large scale usage of these materials in hybrid formats.

\section{Technology Integration}

Integrating online learning platforms with campus technology infrastructure presented another set of challenges. The MOOCs used for this study did not "plug" easily into local learning management systems, and thus extensive efforts were required by Coursera and USM staff to support faculty and to enable students to access their local versions of the online course content. Instructors had to work through questions such as: should they embed links to individual videos and online assessments in the campus LMS course page? Should they simply post one link to Coursera and have students navigate their courses within that platform? Or should they download and embed all desired content from Coursera directly into the campus LMS so that students could find all course materials in one place?

Even once these decisions were made, technology integrations did not always go as planned. Although mechanisms were in place in all but one campus to enable "single sign-on" to the online platforms, many students encountered problems accessing the appropriate versions of the MOOCs. One team of instructors that had planned to use an integrated authentication approach abandoned this solution once the course got underway. In survey responses, 21 percent of free text comments about what could be improved in the course concerned technology.

The Coursera platform was not intended to be used by instructors on campus and thus the features did not meet several of their needs. For example, it was cumbersome to transfer grade information to the local LMS systems and to monitor progress of individual students. While these technical issues were not trivial in this project - and many technical issues also arose with courses using the Open Learning Initiative platform - we expect that they will be relatively straightforward to resolve if the MOOC platform providers decide that institutional licensing is a priority. In addition, technology support at the campus and system levels would have to be reoriented to respond to these needs.

\section{Cost Findings}

One of the most important unanswered questions is whether and how online learning technologies can be used to reduce costs for institutions on a large scale. 
Our colleagues have documented at length the failings of previous studies and technology providers to address this side of the cost/benefit equation. ${ }^{16}$ Programs from the National Center for Academic Transformation indicate the potential for cost savings, but they typically report notional savings on a course-by-course basis and do not address important sustainability issues. ${ }^{17}$

In this project we could not come close to addressing all the questions we would have liked to answer, but we were able to compile a baseline set of data for the time required to redesign and deliver a hybrid course using readily available online course materials. The faculty time spent on planning and teaching is one of the largest determining costs associated with a course, and we focused primarily on understanding how this time is spent and the impact of using online learning platforms.

We observed that it is extremely time consuming to redesign a course using either the Coursera or OLI platform. The median time spent planning for the course among our pool of faculty was 148 hours (and the mean was 175 hours), most of which was spent during the summer before the courses were delivered.

Table 3: Total Course Planning Time in Hours

\begin{tabular}{lllll} 
& Mean & Median & Minimum & Maximum \\
\hline $\begin{array}{l}\text { Case Studies } \\
(7 \text { instructors })\end{array}$ & 169 & 205 & 54 & 256 \\
\hline $\begin{array}{l}\text { Side-By-Side } \\
\begin{array}{l}\text { Courses } \\
(5 \text { instructors })\end{array}\end{array}$ & 180 & 115 & 40 & $506 \dagger$ \\
\hline $\begin{array}{l}\text { Total } \\
(12 \text { instructors })\end{array}$ & 175 & 148 & 40 & $506 \dagger$
\end{tabular}

†This includes extensive time spent creating new content for the online platform.

This is not to say that a course could not be redesigned in less time, as faculty partners focused principally on developing effective courses rather than saving time. Greater use of instructional designers with technical expertise might help to streamline this process. But it does appear that redesigning a course using online technologies requires a different kind of time investment than, say, switching to a new textbook. Many hours are involved in learning the technology platform, making adaptations to online content, and planning how class time will be used and how the pieces of the course will fit together. This finding indicates that faculty members are likely to need incentives, such as relief from other parts of their work load, in order to redesign courses using new technologies.

In spite of the time investment needed for course planning, fourteen instructors in this study believed that they saved time in this iteration of delivering a course or would save time if their course could be offered again, while the rest did not. This is speculation, of course. For future research, it would be desirable to examine

16 Kelly A. Lack, Current Status of Research on Online Learning, March 21 2013. William G. Bowen, Higher Education in the Digital Age, Princeton University Press, 2013.

17 For example, the Colleagues Committed to Redesign program reports that " 26 projects projected cost reductions of $39 \%$ on average, with a range of $9 \%$ to $74 \%$." See http://www.thencat.org/Program_ Outcomes_Summary.html, accessed on May 23, 2014. 
time use over multiple iterations of a course to see whether the up-front investment is recouped over time - and to what degree. It is also important to capture whether reduced class time causes increased student demand for interaction with instructors via email or office hours, as we saw with two courses in which instructors felt they did not have adequate class time.

Most instructors who used the technology to replace some of their usual lecture content spent less time in the classroom than the instructors teaching the control sections. As indicated in Table 3, hybrid sections had on average 72 minutes of class time per week, compared to 126 for traditional sections. We heard a few instances of increased demand for office hours or emails from students in hybrid sections, but these did not form a consistent pattern. Appendix Table 11 provides a detailed breakdown on time spent on course delivery.

We found a startling range in the amount of time spent on course planning, from 40 hours to over 500. These data imply that the time investments depend heavily on the inclinations of individual faculty and on the nature of the course. A rigorous study of the costs of hybrid courses would thus need to examine a much larger population of instructors. These instructors would need to keep careful track of time use, which is not a standard practice for faculty.

We also attempted to document the "ripple effects" that implementation of online learning platforms would cause in other campus unit costs, such as instructional design and administrative services. However, only about half the instructors turned to their institutions' instructional design or technology support staff. Many of them relied on external services for support-either the platform providers or two graduate assistants hired specifically for this study. For those that used internal support, the hours involved were minimal and had little discernible impact on costs. Instructors and administrators also did not report any impacts on other services, such as student support. 
These benefits, however, are

unlikely to be realized or achieve theirfull potential without concerted effort by providers to address certain content and technology issues that, at present, would discourage all but the mostmotivated faculty from attempting to use them.

\section{Lessons Learned}

We return now to the research questions that motivated this study to consider the implications of our findings. This section is informed by our judgment and interpretation of these data, and in some cases what we learned points to the need for further investigation.

How can a primarily direct-to-student MOOC platform be used by institutions
to teach students enrolled in traditional degree programs? to teach students enrolled in traditional degree programs?

Our findings indicate that MOOCs can offer benefits to instructors and students when embedded in campus-based courses. We observed a number of cases in which content from MOOCs addressed a need that could not easily have been met otherwise. These benefits, however, are unlikely to be realized or achieve their full potential without concerted effort by providers to address certain content and technology issues that, at present, would discourage all but the most motivated faculty from attempting to use them. Appropriate incentives and support structures are also needed for individual faculty or departments to make use of these materials.

The ability to customize online content reasonably easily is crucial to adoption of these materials. Our experience suggests that, unless more standardization is brought to the course design and delivery process, few faculty members will choose to teach with MOOCs — or any kind of online courses - that they cannot adapt to their needs. We can imagine a progression in which faculty gain familiarity with what MOOCs can offer (perhaps without the MOOC label) and grow more open to using these materials in different ways to solve problems for their students.

Closing the gap between what online course platforms offer and what instructors need will require convergence from multiple directions: platform and content developers would need to agree to appropriate IP terms and produce content that is more modular and flexible. Platform operators would need to create mechanisms to make institutional licensing simple and transactional, and perhaps even put incentives in place to create the kinds of content that are most needed (e.g. high quality introductory level quantitative courses). In addition, the institutions that are investing heavily in the creation of MOOCs and other online course content would need to decide that it is in their interests to make these materials available for use in other institutions and encourage their faculty to permit these uses.

Finally, faculty and administrators will need to consider ways that available online course materials can be used to meet a variety of instructional needs for their students. Encouraging such adoption would require a system of incentives and rewards for the faculty — and their respective departments— that take fullest 
advantage of such opportunities. This system would have to be established by the administration and aligned with clearly established strategic plans and goals.

What are the learning outcomes from hybrid courses compared to face-to-face instruction?

We did not find any significant differences in measurable outcomes for students in hybrid sections compared to those taught in traditional face-to-face formats. There was no evidence of harm to subgroups such as under-represented minorities, students from low-income families, first-generation college students, first year students, or students with below average SAT scores. This finding is a notable result if one considers that instructors in hybrid sections were teaching their redesigned courses for the very first time, facing considerable implementation challenges, and that these courses had on average 57 percent as much class time as traditional sections.

Students in hybrid sections gave lower ratings than those in traditionally taught sections for how much they enjoyed the course, how much they felt they learned, and how much the course increased their interest in the discipline. On average students reported spending less total time on course work in hybrid sections, including class time. Again, we did not see evidence that students in at-risk subgroups had worse experiences in these courses; if anything their ratings were more positive than other subgroups.

Through these experiments, we learned some important lessons about the research process itself. One key takeaway is that careful planning for the implementation of new course formats and technologies is absolutely critical, and the results of any individual test are influenced by a large variety of factors that have nothing to do with the technology. Another is that research of this nature should plan for multiple iterations when conditions permit. These tests are expensive and challenging to conduct, but there would be significant value in repeating experiments over several years. Course redesigns can take several iterations to fine tune as platforms get better and instructors grow more comfortable with the technology. The hybrid instructors all identified ways in which they thought they could achieve improved outcomes if they were to re-teach their courses. These opportunities for improvement indicate that these results are a baseline for the kinds of outcomes one might expect through the use of these technologies.

What are the strengths and weaknesses of emerging platforms?

Among the platforms involved in these tests, each has particular strengths and areas that may require further development for campus-based use. MOOCs offer rich multi-media content and comprehensive bundles of content including lectures, in-video quizzes, and assessments, produced by accomplished faculty at well-regarded institutions. Instructors from two of the tests noted that they preferred the intellectual quality of the lecture videos in MOOCs to what they perceive as more basic materials available from commercial publishers. Several instructors said that they liked having all the course materials in one environment (in that case Coursera), rather than piecing together a course with resources from multiple providers (such as Khan Academy or Lynda.com). Not surprisingly, MOOC materials seem to work best when the subject is well aligned with an on-campus need and when there is a need for materials to cover an entire course or 
Several faculty expressed a desire

to understand the sustainability

models of the online course

platforms they use so that they can

feel confident that the materials

will continue to be available under

predictable license terms. at least a section of a course, as opposed to a lecture on one specific topic. For these materials to be adopted widely, they would need to integrate more seamlessly with campus systems and offer more modular, flexible content.

The OLI courses are based in principles of learning science and provide ample opportunities for students to work through problems to achieve mastery. They are primarily text-based with interactive learning activities, tutors, simulations, and assessments. They are free to independent learners and in most cases to instructors. One group of instructors said they had chosen this platform in part because they felt comfortable with its academic roots and non-profit status. They were frustrated, however, by the difficulty of customizing the course content. With both OLI and MOOCs, we heard concerns about the long-term availability of the courses. Several faculty expressed a desire to understand the sustainability models of the online course platforms they use so that they can feel confident that the materials will continue to be available under predictable license terms.

The Pearson products used in several pilot tests were designed specifically for use by instructors and presented the fewest implementation challenges. Pearson provides large selections of content and deep banks of practice problems and assessments for quantitative subjects. Pearson has partnered with the provider of an adaptive learning engine, which aims to personalize learning paths for individual students. Instructors involved in three pilot trials were generally pleased with the platform, though they expressed skepticism about the benefits of the underlying adaptive learning technology, observing that students tend to skip around inside the platform to different activities, potentially undermining the benefits of prescribed personalized learning pathways.

Our overall assessment from the tests and pilots conducted in this study is that the general hype about online learning technologies and use of "big data" is still well ahead of reality. The unclear value of the adaptive learning described above is one case in point. We also found that the usage logs obtained from all three types of platforms do not capture certain activities that we wished to analyze and are extremely challenging to manipulate. ${ }^{18}$ More sober appraisals of what these technologies can and cannot do would help to ground conversations and set expectations at realistic levels. This is not to say that the tools are not useful in their current form, but that inflated claims risk disillusionment and ultimately do not serve either providers or users well.

Our experience in this project also reaffirmed a finding from previous research that, even with recent surges in investment, there is a need for more high quality, interactive online courseware available for use in campus-based courses. To cite one data point, when permission was withdrawn to use an introductory level MOOC in our study, we were unable to locate a suitable substitute that covered core concepts in a coherent way. The MOOC may not have been a perfect fit for the faculty partners' needs, but it was better than the alternatives.

18 with our experience, a report from the MOOC Research Initiative describes the difficulty of working with MOOC data. See Carl Staumsheim, "Data, Data Everywhere," Inside Higher Ed, June 10, 2014, http://www.insidehighered.com/news/2014/06/10/after-grappling-data-mooc-researchinitiative-participants-release-results\#sthash.cfcc4cJW.dpbs. 
Because of the difficulty of finding suitable, readily available online content, many instructors are inclined to create their own online content (videos, quizzes, etc.). The appeal is understandable; the number of hours instructors reported spending to adapt online course content are in the same range as the time others spent creating them. ${ }^{19}$ On the other hand, creation of high quality online course materials is a time intensive and costly undertaking, requiring access to teams of instructional designers, technology specialists, videographers, and others. Creating online materials that provide personalized instruction and generate useful data for monitoring student progress requires a very high level of effort and sophistication. Not all institutions can or should make these kinds of capacity investments.

\section{What kinds of costs savings are possible through implementation of these technologies?}

Based on the data we collected, the clearest potential for time savings appears to be in the amount of time instructors spent delivering courses. Those in the treatment sections spent just over half as much time in class as those teaching the control sections. In one large course designed by a single course coordinator, instructors in the MOOC-based sections told us they saved considerable time because they did not need to prepare content to teach and they spent less time in class. Once the initial investment is made in preparing the course, instructors may be able to spend less time planning what to teach and actually coming to class. We also suspect that some of the planning burden could be alleviated through use of course design expertise, so that individual faculty members would not be starting from ground zero and would have help thinking about how the pieces of a course fit together.

In about half the cases, the USM instructors felt that the MOOCs used in their courses were not well suited to their needs or their students' needs. These mismatches, combined with the challenges of using a new technology platform that was not designed for campus use, meant that faculty had to do more work to adapt the content for their courses. It is possible that more fit-for-purpose tools would have enabled the instructors to redesign their courses in less time. Furthermore, the mismatch problem meant that faculty did not take full advantage of some tools provided by the MOOC platform, such as automated grading, which might have contributed to saving time and reducing costs.

As noted above, we were not able to test some of our hypotheses about ways that technology could lower costs. We did not test rigorously the notion that faculty members could teach larger numbers of students with comparable outcomes, or that the flexibility afforded to students through hybrid or online formats could enable them to attain their degrees more successfully and in fewer years. Answering this important question would entail a longitudinal study following a sizable cohort of students through redesigned courses or programs through their college careers. ${ }^{20}$

19 Steve Kolowich, "The Professors Who Make the M00Cs," Chronicle of Higher Education, March 18, 2013, http://chronicle.com/article/The-Professors-Behind-the-M00C/137905/\#id=overview, accessed May 24, 2014. This article reports that professors typically spend around 100 hours creating M00Cs before they launch.

20 We are trying this on a small scale with a test of a low-cost online summer math program, after which we will observe students in treatment and control cohorts to see how they fare in math-related courses during the subsequent year. 


\section{What can be learned through this process and from USM's rich experience implementing new instructional models?}

Because the scope of this study was so large, we gained insight into how a public university system implements new initiatives in teaching and learning. In the end, despite numerous stumbling blocks (e.g. faculty and administrative turnover, withdrawal of permission to use one of the MOOCs), the USM helped us to enlist 31 faculty, design/redesign 21 courses using external technologies, and introduce nearly 1,00o students to new learning tools. All this was achieved in roughly one year. And through this process, the people involved learned a great deal about how to engage in such efforts. We can offer several other broad observations about this change management process.

Support of leadership at multiple levels of administration is necessary but not sufficient. The system chancellor's advocacy of this project was surely a crucial factor in gaining endorsements of presidents, provosts and deans of the individual institutions. Their encouragement set a positive tone for the discussions we had with faculty on campuses, and no doubt gave some faculty members confidence to "take the plunge." The support of department chairs was particularly helpful in navigating logistical issues such as class assignments and room scheduling. These enabling factors are all crucial, but, at the end of the day, the decision of whether or not to participate rests with individual faculty members. This is the case not just for a study, but for any kind of changes to the way courses are taught. We were gratified to see so many of the USM faculty genuinely interested in investing the time and effort necessary to explore new pedagogical tools for the potential benefit of their students.

We also ascertained that course redesigns must be part of broader strategic initiatives in order to have substantial and sustained impact. The USM has been engaged in course redesign and academic transformation initiatives since 2006 as part of its system-wide strategic plan. Innovative efforts by individuals can spread awareness and interest among faculty, but there is a limit to what they can accomplish without connection to broader institutional goals and initiatives. A key question is how to ensure that course redesigns spark or take place within a context of broader and coordinated initiatives that ultimately could re-shape educational production functions. We are convinced, through this and other studies, that very little can be accomplished without effective cultivation of faculty support and appropriate incentives to motivate their participation.

This study showed that a public university system can play a catalytic role in pushing out change across the institutions. We observed that central administrators do this not by exercising top down authority but by initiating or helping to shape strategic initiatives across campuses. For example, the USM chancellor's office has focused on securing philanthropic funding to create incentives for faculty and departments to participate in academic transformation efforts. They have built communities of practice across the system, bringing together faculty that have led course redesign efforts and individuals tasked with coordinating instructional innovation on their respective campuses. The central administrators are well positioned to stay abreast of technology and policy developments at the national level, and we have observed many instances in which they participated in national convenings and brought ideas and opportunities back to the state. Because these 
administrators have such limited direct authority over the way instruction is delivered, it is clear that they must shepherd political capital carefully and deploy it for the most difficult and important challenges. 
Using MOOC and OLI courses

in hybrid formats, faculty were

able to achieve outcomes

comparable to traditionally

taught sections with, on average,

considerably reduced class time.

\section{Summary}

This study aimed to explore both the "what" and the "how" of implementing emerging online learning technologies in more traditional campus environments to address pressing needs in public higher education. Our findings indicate that there are very promising opportunities which merit further exploration. Faculty who participated in the study found that MOOCs could serve as useful tools for accomplishing their goals with students and — perhaps most significantly—most would like to continue using them in the future and would recommend them to their colleagues. All of them identified ways that they could improve upon their courses if they were to teach them again. Using MOOC and OLI courses in hybrid formats, faculty were able to achieve outcomes comparable to traditionally taught sections with, on average, considerably reduced class time. Considering the fact that this was the first time they had taught redesigned courses using these technologies and given the many implementation challenges encountered, this was no small accomplishment.

We do not have conclusive evidence of how use of these technologies on a large scale would impact costs. Instructors spent a great deal of time redesigning their courses and learning to use the new platforms. Still, we see potential to reduce demands on faculty time if these courses are taught multiple times. As participants gain experience with using these tools and integrating them into college and university structures, it may well be possible both to improve outcomes and reduce costs. Substantial cost savings would, we believe, require more strategic use of these tools across departments and institutions. Effective leadership would be essential—significant cost savings are not going to "just happen" on their own.

Many organizational and external issues will need to be addressed to take full advantage of these technologies. Faculty need assurances that these materials will continue to be available for use, technically reliable, and adequately supported for multiple iterations. At present, however, there is uncertainty about the ownership of MOOCs and about the sustainability of these materials, as well as many other open educational resources. Faculty must have the ability to customize course content, and this too is not assured. They need access to a greater selection of online content and better indexing so that these materials are easier to locate, reducing the amount of work required to fit the online materials with their courses and improving the student experience. More modular, flexible online resources would also make the implementation process easier.

While many innovative faculty members-including those who participated in this study - have demonstrated great creativity and willingness to try new approaches with technology, these individual efforts can only be sustained and achieve large scale impact within a coherent strategic framework. Administrators 
at the institutional and system level must provide the necessary incentives, rewards, and support structures without which it is hard to imagine any significant progress. Ultimately, faculty must be willing to try using materials created elsewhere and be open to the potential benefits these materials can offer their students. 


\section{Appendices}




\section{Appendix A: More Detail on Side- by-Side Tests}

Appendix Table 1: Overview of side-by-side tests:

\begin{tabular}{|c|c|c|c|c|c|c|c|c|}
\hline Course & Technology & $\begin{array}{l}\text { Format } \\
\text { Notes }\end{array}$ & $\begin{array}{l}\text { Number of } \\
\text { Treatment } \\
\text { Sections }\end{array}$ & $\begin{array}{l}\text { Students in } \\
\text { Treatment } \\
\text { Sections }\end{array}$ & $\begin{array}{l}\text { Students in } \\
\text { Control Sec- } \\
\text { tions }\end{array}$ & $\begin{array}{l}\text { Minutes } \\
\text { per Week } \\
\text { Treatment } \\
\text { Section Met }\end{array}$ & $\begin{array}{l}\text { Minutes per } \\
\text { Week Control } \\
\text { Section Met }\end{array}$ & $\begin{array}{l}\text { Outcome } \\
\text { Measure }\end{array}$ \\
\hline Biology $B$ & OLI & & 3 & 88 & 80 & 50 & 150 & None \\
\hline Statistics & MOOC & Supplemental & 2 & 64 & 64 & 150 & 150 & $\begin{array}{l}\text { Post-test; } \\
\text { Common final }\end{array}$ \\
\hline Pre-Calculus & MOOC & & 2 & 55 & 67 & 120 & 220 & $\begin{array}{l}\text { Post-test; } \\
\text { Common final }\end{array}$ \\
\hline $\begin{array}{l}\text { Computer } \\
\text { Science }\end{array}$ & MOOC & & 4 & 92 & 84 & $75-100$ & 150 & $\begin{array}{l}\text { Common } \\
\text { midterm }\end{array}$ \\
\hline
\end{tabular}

Notes: In four courses, the instructor(s) for the treatment section differed from those of the control section. Students in four of the seven side-by-side tests were unaware of the differences in section formats before the first day. For the other three courses, first-year students had limited choice over their sections given that they registered shortly before classes began.

\section{Data Collected}

Participating institutions provided administrative data related to academic preparation and demographic characteristics for all students in treatment and control groups. Students who consented to participate in the study were asked to complete surveys designed to solicit additional information about their backgrounds (e.g. parental education and family income), as well as interest in the course subject and their experiences in the course. Surveys were conducted in control sections as well as treatment sections. We allowed the institutions discretion over whether to offer small incentives to students for participation, and three tests chose to do so.

Due to the range of courses involved, we could not implement a uniform post-test. Instructors for each course determined what their students should learn and designed assessments according to those standards. We asked treatment and control group instructors to agree on common exams or at least a significant subset of common questions on exams, and these are the primary outcome measure. We also obtained pass rates and grades, which can be subject to variations in grading standards among instructors. Although no single measure 
provides a perfect assessment of student performance, we believe that taken together these three measures provide a reasonable assessment of student performance. Moreover, we saw consistency in these three measures for most courses.

One course was unable to provide us reliable post-tests because the instructor thought that the post-tests did not equally assess material covered in the treatment and control sections. This course is excluded from the common exam/ post-test analyses.

We surveyed instructors from all sections to obtain data about their teaching experience and background in order to help us compare the differences in instructor characteristics across the sections.

\section{Results}

In this section we report, in more detail, the analyses on which the findings in the main body of the report are based, as well as the results of some additional analyses.

Appendix Table 2 shows that controlling for SAT scores, cumulative GPA at the beginning of the semester, race/ethnicity, gender, parental income, and student age, changes our estimate of the effect on pass rates from 3.6 to 3.0 percentage points, and leaves the estimate for the post-test/final unchanged at 2.4 percentage points. We obtain qualitatively similar results for pass rates when we use a probit model instead of a linear probability model. (This table also shows little differences in course grades, a more subjective measure that we report but that is not a primary focus of our analysis.)

Appendix Table $2 \dagger$. Difference between outcomes in hybrid and traditional sections, all courses

\begin{tabular}{lllllll} 
& Pass & & $\begin{array}{l}\text { Post-test/ } \\
\text { Final }\end{array}$ & & $\begin{array}{l}\text { Course } \\
\text { Grade }\end{array}$ \\
\hline Hybrid effect & 0.036 & 0.030 & $0.024^{*}$ & $0.024^{*}$ & -0.002 & -0.024 \\
\hline & $(0.033)$ & $(0.032)$ & $(0.014)$ & $(0.012)$ & $(0.176)$ & $(0.169)$ \\
\hline Controls? & No & Yes & No & Yes & No & Yes \\
\hline Observations & 1,594 & 1,594 & 1,187 & 1,187 & 1,564 & 1,564 \\
\hline Control mean & 0.83 & 0.83 & 0.70 & 0.70 & 2.21 & 2.21 \\
\hline Control std dev & & & 0.16 & 0.16 & 1.34 & 1.34
\end{tabular}

Notes: $\uparrow$ Several questions are adapted from the National Survey of Student Engagement. We have obtained permission to use these questions.

*** $p<0.01,{ }^{* *} p<0.05,{ }^{*} p<0.1$; Robust standard errors adjusted for clustering by section appear in parentheses. All models include dummies for each course. Controls include SAT math and verbal scores, cumulative GPA at the beginning of the semester, race/ethnicity, gender, parents' income, and age. Missing values are identified by dummies for each variable, with continuous variables imputed using an arbitrary value (in this case, zero). The course grade is measured on a four point scale.

Appendix Table 3 shows differences in student outcomes between section types separately for each course, taking into account the controls listed above.

For example, the upper-left coefficient estimate of 0.038 indicates that, in the communications course, pass rates were 3.8 percentage points higher in the hybrid 
sections than in the traditional sections (which had a pass rate of 89 percent, as indicated by the control mean of 0.89 in the table).

Appendix Table 3. Difference between outcomes in hybrid and traditional sections, by course

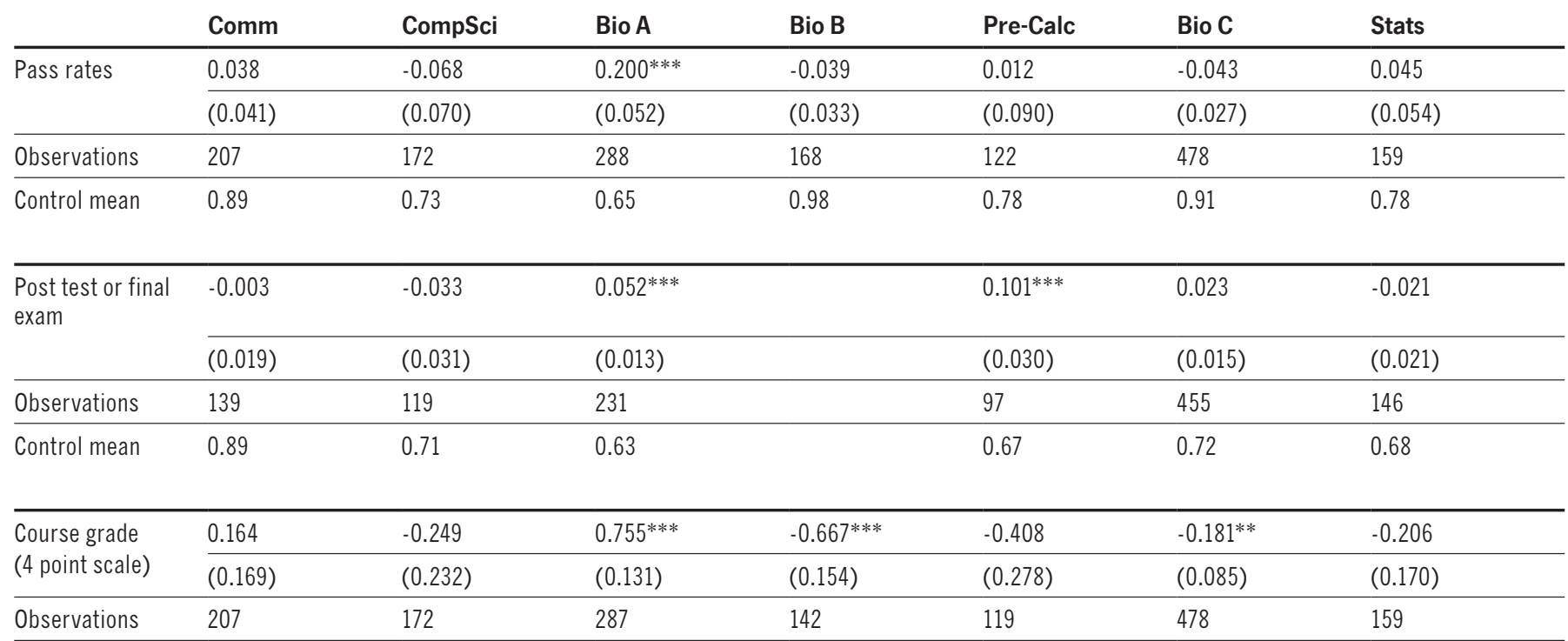

Notes: ${ }^{* * *} p<0.01,{ }^{* *} p<0.05,{ }^{*} p<0.1$; Robust standard errors appear in parentheses. All models include controls for SAT math and verbal scores, cumulative GPA at the beginning of the semester, race/ethnicity, gender, parental income, and age. Missing values are identified by dummies for each variable, with continuous variables imputed using an arbitrary value (in this case, zero).

In general, the results for pass rates and final assessment scores indicate a mix of small positive and small negative results. In most cases, these results are not statistically distinguishable from a zero effect (i.e. no difference between the formats), which is not surprising given that each individual test was relatively small. However, there are a couple of exceptions. There was a large difference in pass rates (2o percentage points) favoring the hybrid sections of one course. Discussions with campus faculty suggest that this was due to very stringent grading standards imposed by the instructor of the traditional section, which have historically led to low pass rates. However, the hybrid students also performed better on the common exam questions, a measure that should not be affected by instructor grading standards. There was also a significant positive estimated effect on final exam scores in the pre-calculus course of about 10 percentage points. There are a number of smaller estimated hybrid effects, both negative and positive, but given the precision of the analysis for an individual course we cannot be confident about the direction (negative or positive) much less the size of the effect. For example, the estimated effect for computer science implies that the hybrid format lowered pass rates by about 7 percentage points. But, given the precision of the estimate (i.e., the standard error of 0.07), we can only be 90 percent confident that the true effect lies somewhere between negative 18 percentage points and positive 4 points. Our best guess is that the hybrid format lowered completion rates, but more data would be needed to increase our confidence in that finding. 
The course-specific results take into account a number of student characteristics, as noted above. However, we obtain qualitatively similar results when we just look at raw differences in outcomes (not shown). ${ }^{21}$ In other words, there does not appear to be a substantial amount of bias in the results due to different kinds of students choosing the hybrid vs. traditional sections, even when we look separately at each course rather than averaging them all together.

We next estimate hybrid effects, averaged across all seven courses, for various subgroups of students defined in terms of demographics and academic preparation. Appendix Table 4 shows that our main finding of null or weakly positive effects of the hybrid format holds across the full range of student groups. It is important not to over-interpret any single result, especially when results are estimated for a large number of subgroups for multiple outcomes. Positive and negative effects can appear by random chance, and the likelihood of finding such spurious effects increases as more effects are estimated. However, students from low-income families, under-represented minorities, first generation college students, or those with weaker academic preparation fared as well or slightly better in hybrid sections. Perhaps most significantly, we do not find any evidence that poorly prepared students, as identified by below-average SAT scores, are harmed by the hybrid format. At a minimum, the nearly complete absence of negative effects is a robust finding. Thus, the worry that disadvantaged students are most likely to be harmed by technology-enhanced education is also not borne out by our data. If anything, we find the opposite.

21 These results are available from the authors upon request. The only notable exception to the similarity in results is the estimate for pass rates in the statistics course, which is 0.127 (and statistically significant) without controls and 0.045 (but not statistically significant) with controls. 
Appendix Table 4. Difference between outcomes in hybrid and traditional sections, by student subgroup

\begin{tabular}{|c|c|c|c|c|c|}
\hline & Pass & Post/Final & & Pass & Post/Final \\
\hline \multirow[t]{2}{*}{ White/Asian } & 0.037 & $0.031^{* *}$ & \multirow{2}{*}{$\begin{array}{l}\text { Parents' income } \\
\text { less than } \$ 50,000\end{array}$} & $0.099 *$ & $0.060 * *$ \\
\hline & $(0.029)$ & $(0.012)$ & & $(0.050)$ & $(0.025)$ \\
\hline \multirow[t]{2}{*}{ Black/Hispanic } & -0.003 & 0.014 & \multirow{2}{*}{$\begin{array}{l}\text { Parents' income } \\
\$ 50,000-\$ 100,000\end{array}$} & 0.037 & $0.040 * * *$ \\
\hline & $(0.048)$ & $(0.024)$ & & $(0.045)$ & $(0.010)$ \\
\hline \multirow{2}{*}{ Female } & $(0.033)$ & $(0.014)$ & \multirow{2}{*}{$\begin{array}{l}\text { Parents' income } \\
\text { more than } \$ 100,000\end{array}$} & $(0.024)$ & $(0.015)$ \\
\hline & 964 & 712 & & 556 & 417 \\
\hline \multirow[t]{2}{*}{ Male } & 0.018 & 0.010 & \multirow{2}{*}{$\begin{array}{l}\text { Neither parent } \\
\text { has BA }\end{array}$} & 0.094 & 0.038 \\
\hline & $(0.036)$ & $(0.017)$ & & $(0.074)$ & $(0.024)$ \\
\hline First-year student & 628 & 514 & $\begin{array}{l}\text { At least one parent } \\
\text { has BA }\end{array}$ & 657 & 499 \\
\hline \multirow{6}{*}{$\begin{array}{l}\text { Not a first-year } \\
\text { student }\end{array}$} & 0.030 & 0.031 & \multirow[t]{3}{*}{ SAT less than 1000} & 0.019 & 0.025 \\
\hline & $(0.041)$ & $(0.019)$ & & $(0.039)$ & $(0.018)$ \\
\hline & 966 & 673 & & 852 & 625 \\
\hline & & & \multirow[t]{3}{*}{ SAT 1000 or higher } & 0.040 & $0.028 * *$ \\
\hline & & & & $(0.032)$ & $(0.012)$ \\
\hline & & & & 742 & 562 \\
\hline
\end{tabular}

Notes: ${ }^{* *} p<0.01,{ }^{* *} p<0.05,{ }^{*} p<0.1$; Robust standard errors adjusted for clustering by section appear in parentheses. Numbers of observations appear in italics. All models include controls for SAT math and verbal scores, cumulative GPA at the beginning of the semester, race/ethnicity, gender, parents' income, and age. Missing values are identified by dummies for each variable, with continuous variables imputed using an arbitrary value (in this case, zero).

Finally, we conduct several additional analyses, in part as a check on the robustness of our main results. These estimates are reported in Appendix Table 5. The first row displays our main results (with controls included). The second row adds controls for section size and two instructor characteristics: tenure-track status and years of teaching experience. This analysis is a crude attempt to adjust for any differences in the kinds of instructors that volunteered to teach a hybrid section as part of our study, relative to the instructors who continued to teach in the traditional manner. The estimated effects only change modestly, and they indicate potentially larger effects than our main results. 


\begin{tabular}{|c|c|c|c|}
\hline \multicolumn{4}{|c|}{ Appendix Table 5. Robustness Checks and Additional Analyses } \\
\hline & Pass & Post/Final & Grade \\
\hline \multirow[t]{3}{*}{ Main results } & 0.030 & $0.024 *$ & -0.024 \\
\hline & $(0.032)$ & $(0.012)$ & $(0.169)$ \\
\hline & 1,594 & 1,187 & 1,564 \\
\hline \multirow[t]{3}{*}{ Add instructor controls } & 0.037 & $0.039 * * *$ & -0.017 \\
\hline & $(0.028)$ & $(0.012)$ & $(0.165)$ \\
\hline & 1,554 & 1,152 & 1,524 \\
\hline \multirow[t]{3}{*}{ Pre-test control } & 0.009 & 0.017 & -0.107 \\
\hline & $(0.036)$ & $(0.013)$ & $(0.178)$ \\
\hline & 1,594 & 1,187 & 1,564 \\
\hline \multirow[t]{3}{*}{ Coursera only } & 0.013 & 0.000 & -0.132 \\
\hline & $(0.040)$ & $(0.020)$ & $(0.187)$ \\
\hline & 660 & 501 & 657 \\
\hline \multirow[t]{3}{*}{ OLI only } & 0.040 & $0.039 *$ & 0.049 \\
\hline & $(0.049)$ & $(0.016)$ & $(0.257)$ \\
\hline & 934 & 686 & 907 \\
\hline \multirow[t]{3}{*}{ Drop Bio A } & -0.009 & 0.012 & -0.211 \\
\hline & $(0.026)$ & $(0.013)$ & $(0.152)$ \\
\hline & 1,306 & 956 & 1,277 \\
\hline \multirow[t]{3}{*}{ Drop Stats and Bio C } & 0.044 & $0.030 *$ & 0.036 \\
\hline & $(0.043)$ & $(0.016)$ & $(0.216)$ \\
\hline & 957 & 586 & 927 \\
\hline
\end{tabular}

Notes: ${ }^{* * *} p<0.01$, ${ }^{* *} p<0.05,{ }^{*} p<0.1$; Robust standard errors adjusted for clustering by section appear in parentheses. Number of observations appears in italics. All models include dummies for each course. All models include student controls, including SAT math and verbal scores, cumulative GPA at the beginning of the semester, race/ethnicity, gender, parents' income, and age. Missing values are identified by dummies for each variable, with continuous variables imputed using an arbitrary value (in this case, zero). Instructor controls include tenure-track status, section size, and years of teaching experience.

The third row shows results that add a control for students' scores on a pre-test administered at the beginning of the semester. Pre-test scores were modestly higher in the hybrid sections, where students scored an average of 52 percent correct, than in the traditional sections, where the average score was 47 percent. However, 27 percent of hybrid-format student did not take the pre-test, as compared to 33 percent of traditional-format students. We do not use the pre-test as a control in our preferred results due to the difference in missing data rates between the groups. However, the estimated hybrid effect is only slightly smaller when we include this variable as a control.

The fourth and fifth rows show separate results for the Coursera- and OLIbased tests, respectively. As discussed above, the results are modestly different but not statistically distinguishable from each other. 
The sixth row of Appendix Table 5 shows results for six courses, where the excluded course showed a large effect on pass rates because of the tough grading standards of the traditional-format instructor. Removing this test from the average reduces the estimates to close to zero. The final row shows results for five courses, where the excluded courses are the two that did not reduce face-to-face time in the hybrid sections (statistics and biology C). The results are slightly larger than our main results, suggesting that the maintenance of face-to-face time in two of the courses was not a key driver of our finding of overall positive results.

\section{Survey Results}

In the final surveys, students were asked questions about the course on a five point scale, where one is the worst rating and five is the best. Overall, traditional-format students gave the course a higher rating than hybrid-format students and said that they felt they learned more. There were no significant differences between formats in student reports of the difficulty of the course or how much it raised their interest in the subject matter. We also asked students about the educational value of the different components of the course, the frequency the course emphasized different activities, and how they would rate the technology component (Appendix Figures 1, 2, and 3). Students rated in-class activities as having more educational value than online materials.

Appendix Table 6. Difference between student evaluations in hybrid and traditional sections, all courses

\begin{tabular}{llllll} 
& Hrs $/$ Wk & Overall & Interest & Learn & Difficulty \\
\hline Hybrid effect & 0.2 & $-0.6^{* * *}$ & -0.1 & $-0.4^{* * *}$ & 0.1 \\
\cline { 2 - 6 } & $(0.4)$ & $(0.1)$ & $(0.1)$ & $(0.1)$ & $(0.1)$ \\
\hline Observations & 1,126 & 1,196 & 1,199 & 1,191 & 1,200 \\
\hline Control mean & 4.3 & 3.5 & 2.9 & 3.6 & 3.2 \\
\hline Control std dev & 3.6 & 1.0 & 1.2 & 1.0 & 1.0
\end{tabular}

Notes: ${ }^{* *} p<0.01,{ }^{* *} p<0.05,{ }^{*} p<0.1$; Robust standard errors adjusted for clustering by section appear in parentheses. All models include dummies for each course. 
ONLINE DISCUSSION FORUMS

ONLINE PROBLEM SETS

ONLINE QUIZZES

IN-CLASS ACTIVITIES

HOMEWORK ASSIGNMENTS

TEXTB00K

OFFICE HOURS

EXAMS

MEMORIZING MATERIAL

APPLYING MATERIAL TO PRACTICAL PROBLEMS

ANALYZING AN IDEA

EVALUATING A POINT OF VIEW

FORMING A NEW IDEA
3.2

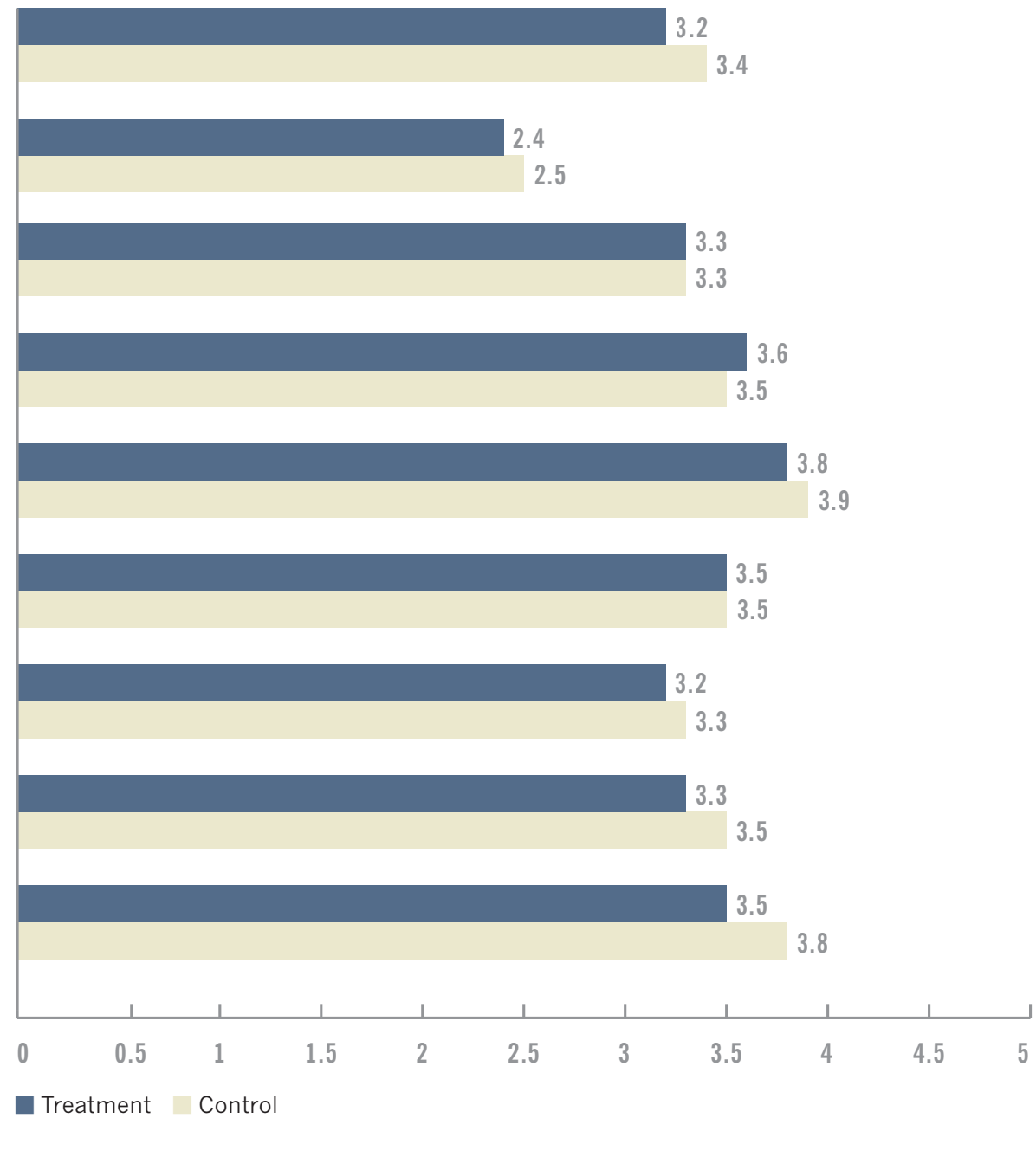

Appendix Figure 2: Frequency Course Emphasized the Following — SBS Tests †

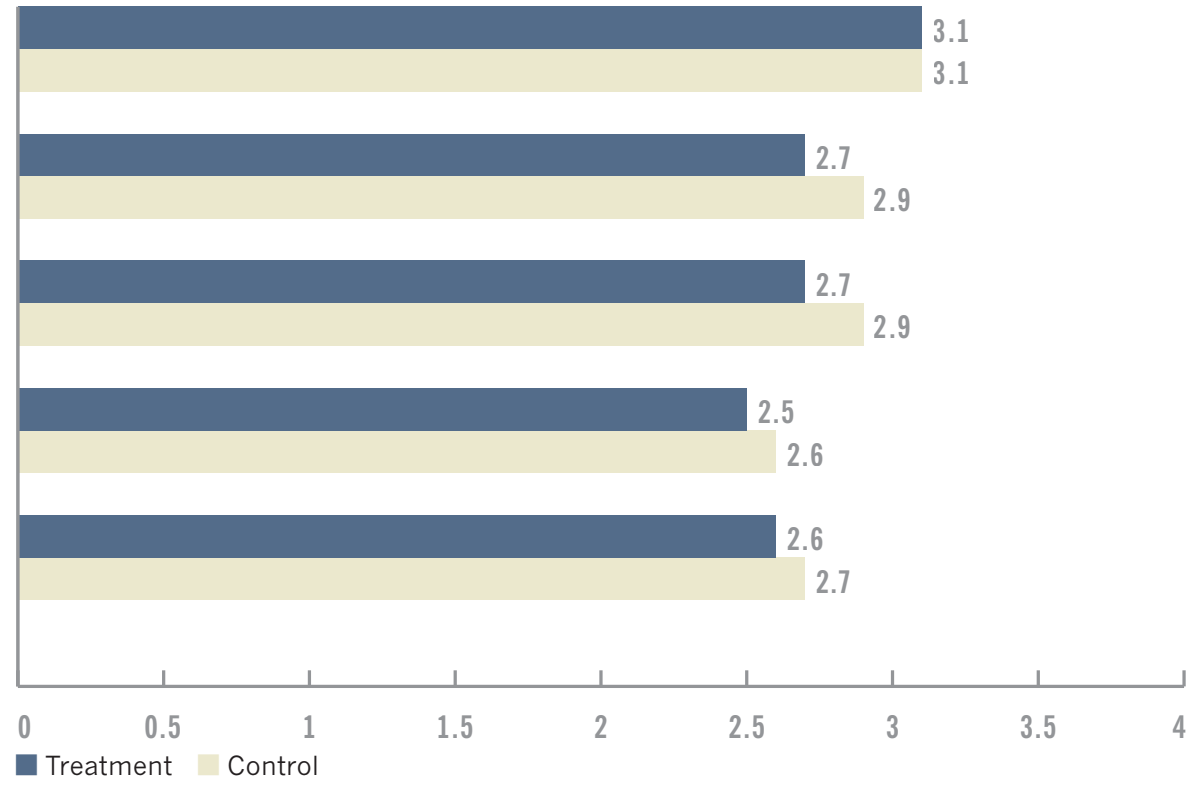

Note: $\nmid$ Several questions are adapted from the National Survey of Student Engagement. We have obtained permission to use these questions.

Interactive Online Learning on Campus 
Appendix Figure 3: Average Ratings Related to MOOC/OLI -

SBS Tests Treatment Sections

MADE COURSE MORE ENJOYABLE THAN F2F

MATERIALS NOT MEANT FOR ME

LEARNED A GREAT DEAL FROM MOOC/OLI

CONFUSING TO HAVE DIFFERENT INSTRUCTORS

HARD TO STAY MOTIVATED

MATERIALS WERE ENGAGING

HIGH QUALITY

LEARNED PRIMARILY FROM MOOC/OL

LEARNED PRIMARILY FROM INSTRUCTOR

DIFFICULT TO FOLLOW

NOT APPROPRIATE FOR MY CLASS

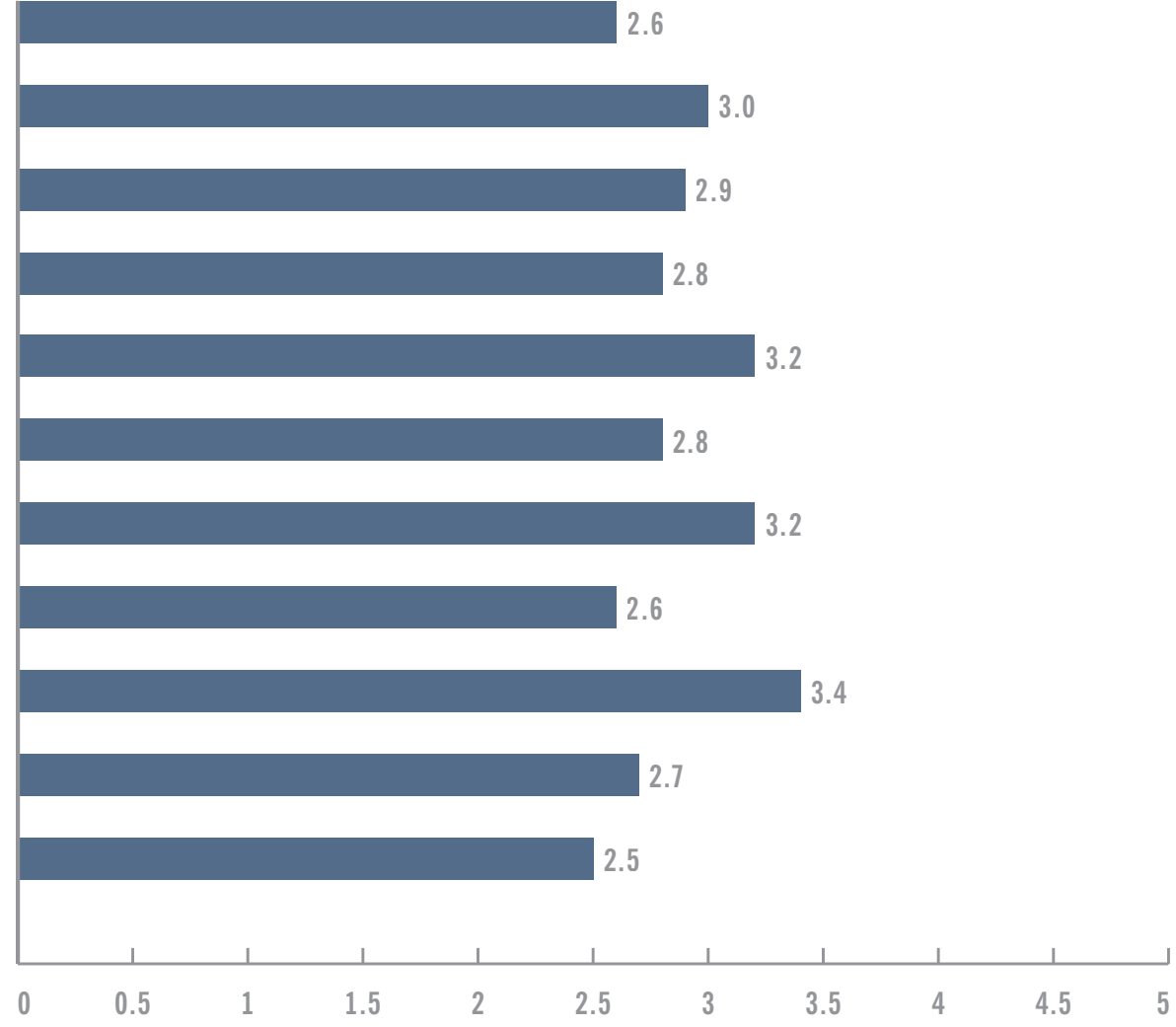

The final course survey asked students in both the treatment and control sections what they felt could be improved in the class. $76 \%$ of students in the treatment sections and $78 \%$ in the control sections responded. The students in the control sections were more likely to say nothing needed to be improved (12\% vs. $6 \%$ ), and the most frequent comments in the treatment and control sections were about improving the course structure (the lecture, assignments, and alignment of materials); $42 \%$ of treatment section comments and $62 \%$ of control section comments were in this category. The students in the treatment sections also expressed desire for more class time (14\%), or an improved technology component (21\%), while $0 \%$ of students in the control sections commented on these. More than half of the comments were negative comments about the technology component or hybrid format.

Technical difficulties were frequently cited by students in free text responses on the survey, accounting for $21 \%$ of the comments about what could be improved in the course. Students' most common comments about their technical difficulties in the course were related to the site crashing (31\%), issues with quizzes (17\%), their internet connection (12\%) and login/access to the platform (11\%). These technical issues may have exacerbated student dissatisfaction with some hybrid courses, particularly with the OLI-based ones, as $67 \%$ of complaints about technology came from students in sections using OLI. 
We examined whether these differences in student satisfaction varied across courses and student subgroups (not shown). ${ }^{22}$ We found a substantial negative perception of the hybrid format (a difference of roughly one point on the five-point scale) in four of the seven courses, with the other three showing only small differences. When we look at perceptions of the same 13 student subgroups we examined earlier, we find a negative effect of the hybrid format on overall satisfaction for all of them, with, if anything, slightly less negative ratings by at-risk student subgroups.

Appendix Table 7: Difference between student evaluations in hybrid and traditional sections, MOOCs only

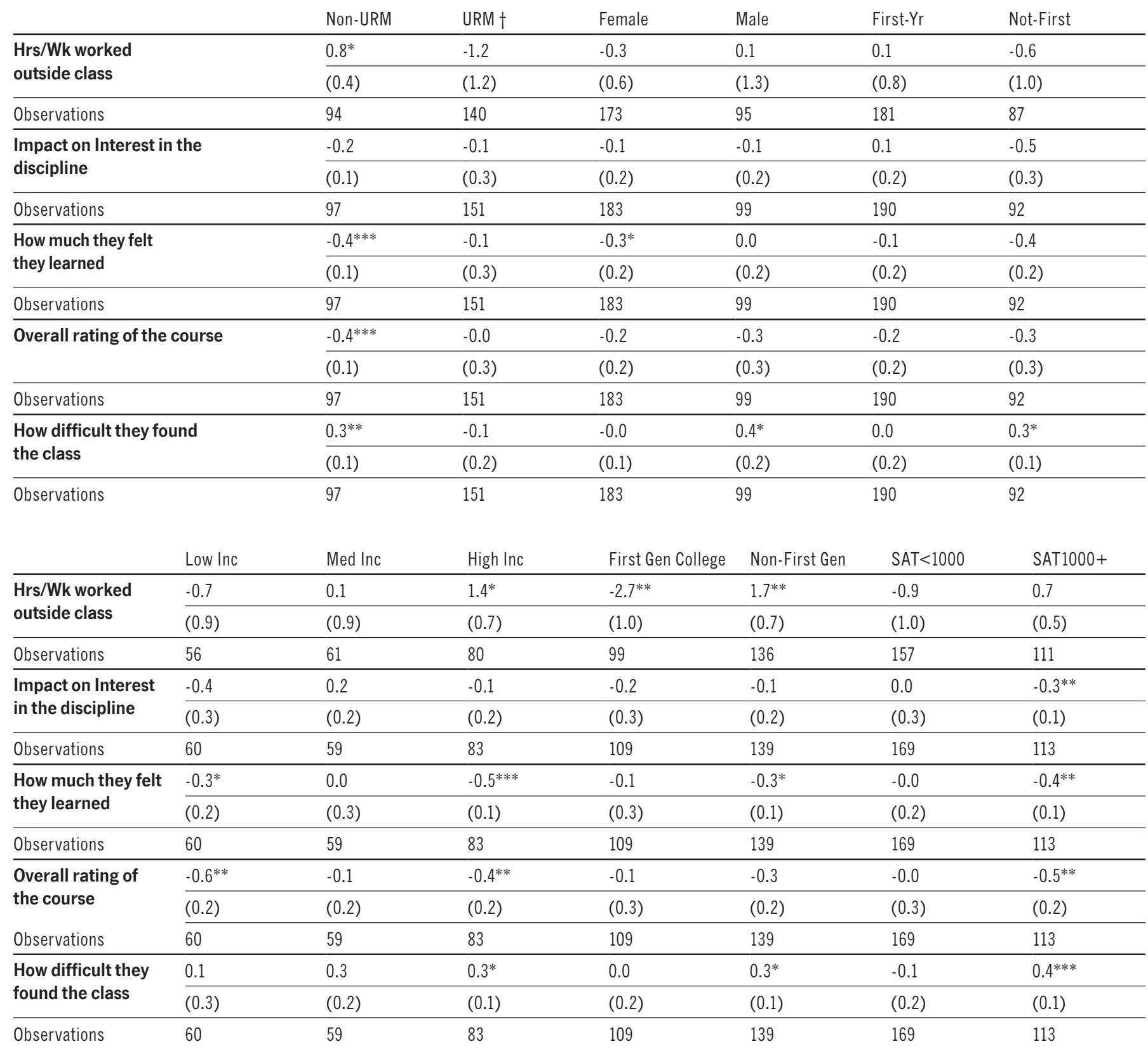

Notes: $\dagger$ URM stands for under-represented minorities. ${ }^{* *} p<0.01,{ }^{* *} p<0.05,{ }^{*} p<0.1$; Robust standard errors appear in parentheses.

22 These results can be obtained upon request. 
Finally, we analyzed how much time students spent working on course material. Appendix Figure 4 shows that the hybrid sections met for roughly one hour less than the traditional sections, but hybrid-format students reported spending about the same amount of time outside of class, on average, as the traditional students.

Appendix Figure 4. Student Time Spent on Course

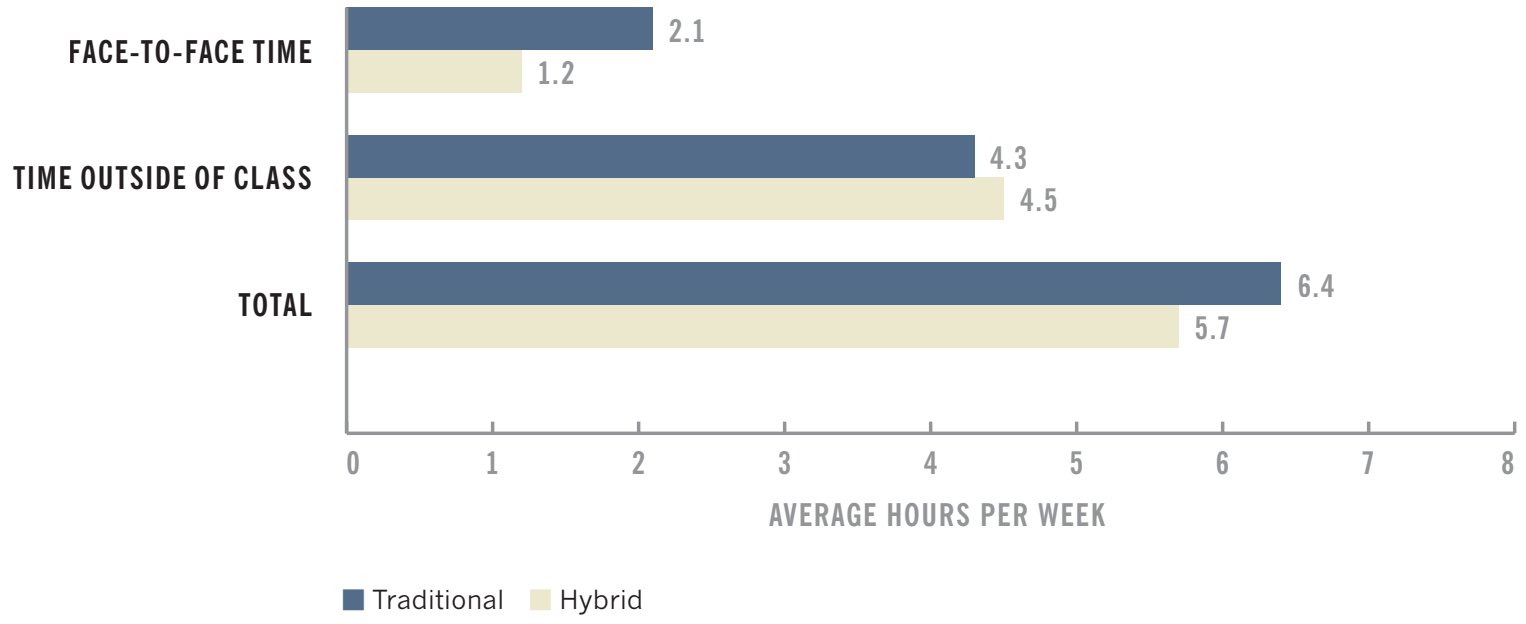




\section{Appendix B: More Detail on Case Studies}

We conducted ten case studies using MOOCs in courses that did not allow for rigorous evaluation of learning outcomes due to smaller course enrollments. The purpose of the case studies was instead to deepen our understanding of the implementation process, to explore ways that MOOCs could be used to enhance teaching and learning in different types of courses, and to gain insight into student and instructor experiences in a larger set of instances. While instructors have views as to whether student learning benefitted from the use of MOOCs, we cannot compare them to a reference cohort, thus we do not report passing rates or grades for these courses.

Case studies covered a variety of levels and subjects, from advanced humanities and art courses to first year seminars in literature and psychology. Sizes ranged from six students up to sixty. Instructors used MOOCs to replace some of the course content or enhance the existing course materials. One of these courses was entirely online, and in another students enrolled in the public offering of the MOOC and engaged in parallel seminar discussions and assessments at their own institution.

\begin{tabular}{|c|c|c|c|c|}
\hline Course & Format Notes & $\begin{array}{l}\text { Number of } \\
\text { Sections }\end{array}$ & $\begin{array}{l}\text { Number } \\
\text { of Students }\end{array}$ & $\begin{array}{l}\text { Minutes per } \\
\text { Week They Met }\end{array}$ \\
\hline Art & $\begin{array}{l}\text { MOOC used for content } \\
\text { portion. }\end{array}$ & 1 & 9 & 160 \\
\hline Poetry & $\begin{array}{l}\text { Live Public Offering of } \\
\text { the MOOC }\end{array}$ & 1 & 11 & 150 \\
\hline Genetics & $\begin{array}{l}\text { MOOC used to replace } \\
\text { some lectures. }\end{array}$ & 1 & 60 & $75-150$ \\
\hline $\begin{array}{l}\text { Psychology } \\
\text { Learning } \\
\text { Community }\end{array}$ & $\begin{array}{l}\text { MOOC used to replace } \\
\text { some content in two } \\
\text { courses. }\end{array}$ & 2 courses & 24 & 250 \\
\hline $\begin{array}{l}\text { Information } \\
\text { Technology }\end{array}$ & $\begin{array}{l}\text { MOOC replaced middle } \\
\text { third of the course. }\end{array}$ & 1 & 19 & $\begin{array}{l}0 \text { or } 150 \text { depending } \\
\text { on the week }\end{array}$ \\
\hline Political Science & Supplemental & 1 & 11 & 150 \\
\hline $\begin{array}{l}\text { English Learning } \\
\text { Community A }\end{array}$ & $\begin{array}{l}\text { M00C was used as a } \\
\text { common experience } \\
\text { across } 3 \text { courses. }\end{array}$ & 3 courses & 17 & 210 \\
\hline Philosophy & $\begin{array}{l}\text { Summer Pilot, Entirely } \\
\text { Online }\end{array}$ & 1 & 6 & 0 \\
\hline Literature & $\begin{array}{l}\text { Two MOOCs used to } \\
\text { provide greater insight } \\
\text { into ancient mythology }\end{array}$ & 1 & 17 & 150 \\
\hline $\begin{array}{l}\text { English Learning } \\
\text { Community } B\end{array}$ & $\begin{array}{l}\text { MOOC was used to } \\
\text { provide context to the } \\
\text { literature covered in } \\
\text { class. }\end{array}$ & 1 & 19 & 150 \\
\hline
\end{tabular}


Data collection consisted of:

- Initial interviews at the end of the planning phase of the project. These explored the instructor's goals for use of the online content, his/her approach to using the online content, which elements were incorporated into his/her course, their course format, and the kinds of challenges encountered with technology integration. Responses to standardized questions were tabulated.

- Final interviews with instructors after the end of the course. In these interviews we probed topics such as whether the course delivery followed the initial plan, what changes they made and why, whether they felt they had achieved their goals in using the online content, what worked or did not work well, and how they thought students responded to the online content and why. We asked each instructor a standard set of questions such as whether they would like to teach again using a MOOC, whether they would recommend this to their colleagues, and what about MOOCs scared or excited them. Responses to standardized questions were tabulated, as were certain types of comments.

- Interviews with support staff such as instructional technologists and IT staff to explore the kinds of implementation issues that arose and how they interacted with faculty.

- Timesheets capturing time use for the planning and delivery stages of the courses. These were submitted by eight out of ten instructors.

- Surveys of students roughly one week before the end of the semester. These asked questions about students' experiences in the course and were similar to the surveys administered in the side-by-side tests.

\section{Findings}

For the case study courses, student ratings across all questions were mostly in the range of 3 to 4 on a 5-point scale, 5 being the best. We did not have control sections for these courses and cannot say whether these responses reflect the use of online materials or other factors, such as small class sizes or the fact that many case study courses were electives. Unlike in the side-by-side comparison tests, students gave roughly equal ratings to the educational value of lecture videos and in-class activities in case studies. The ratings given by students in case study courses matched or slightly exceeded the average ratings given to traditionally taught sections from the side-by-side tests.

The following charts present averages of student responses to survey questions: 


\section{WEEKLY HOURS OUTSIDE CLASS \\ INCREASE INTEREST IN DISCIPLINE \\ AMOUNT LEARNED \\ COURSE RATING \\ COURSE DIFFICULTY}

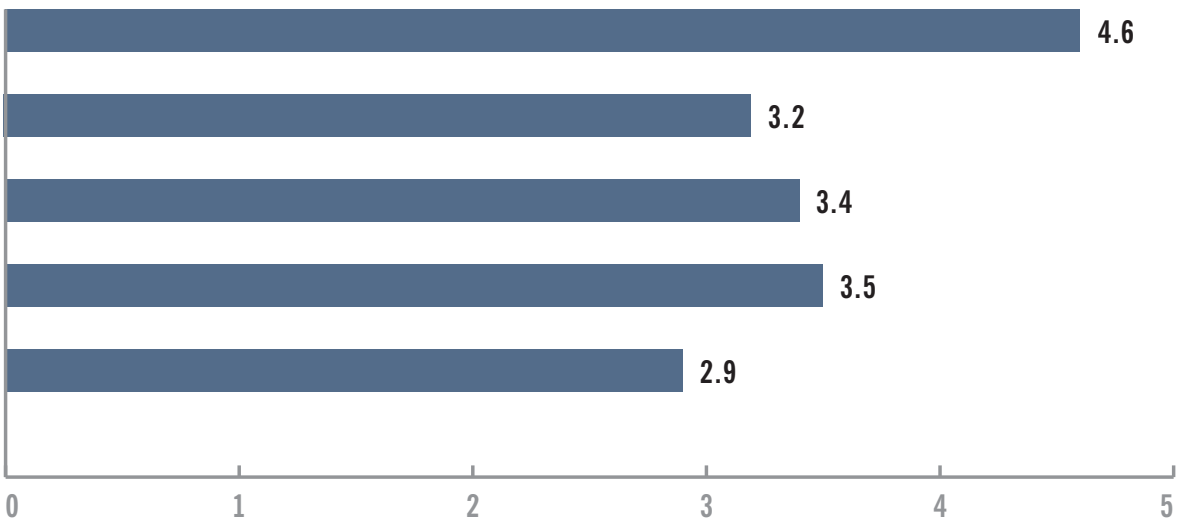

Appendix Figure 6: Average Rating of Educational Value of Course Component Case Studies

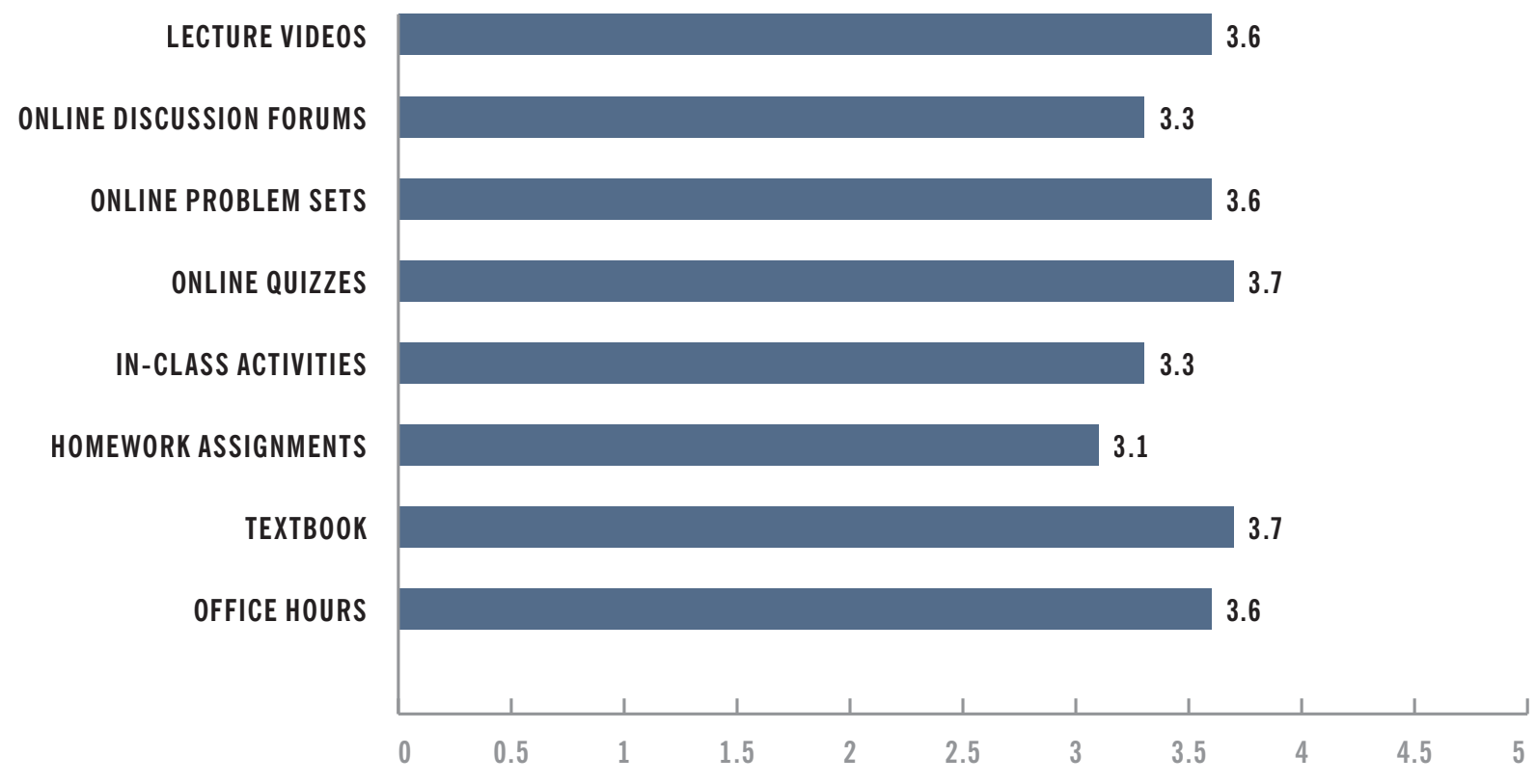


Appendix Figure 7: Average Ratings Related to MOOC

MADE COURSE MORE ENJOYABLE THAN F2F

MATERIALS NOT MEANT FOR ME

LEARNED A GREAT DEAL FROM MOOC

CONFUSING TO HAVE DIFFERENT INSTRUCTORS

HARD TO STAY MOTIVATED

MATERIALS WERE ENGAGING

HIGH QUALITY

LEARNED PRIMARILY FROM MOOC

LEARNED PRIMARILY FROM INSTRUCTOR

DIFFICULT TO FOLLOW

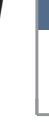
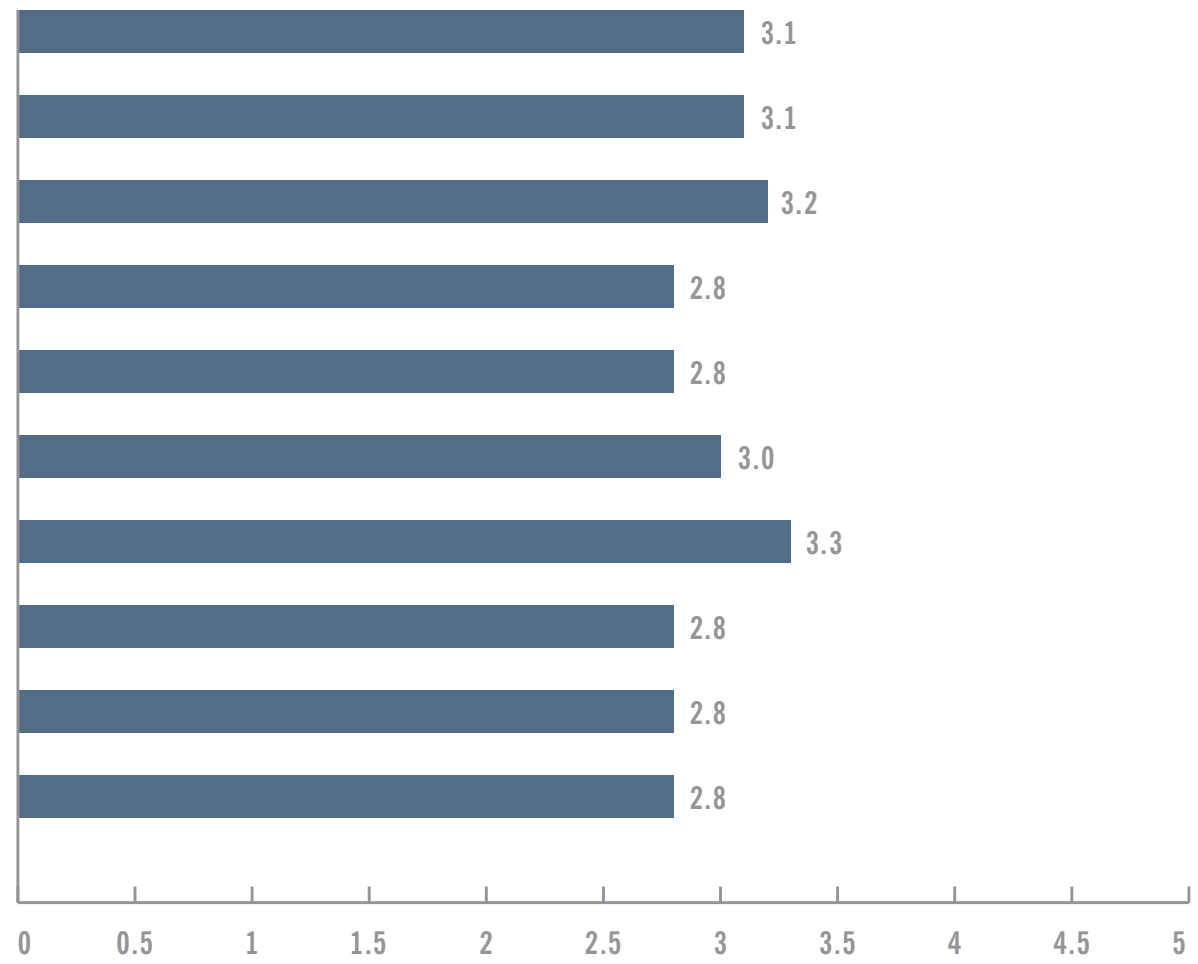

Appendix Figure 8: Frequency Course Emphasized the Following - Case Studies †

MEMORIZING MATERIAL

APPLYING MATERIALS TO PRACTICAL PROBLEMS

ANALYZING AN IDEA

EVALUATING A POINT OF VIEW

FORMING A NEW IDEA

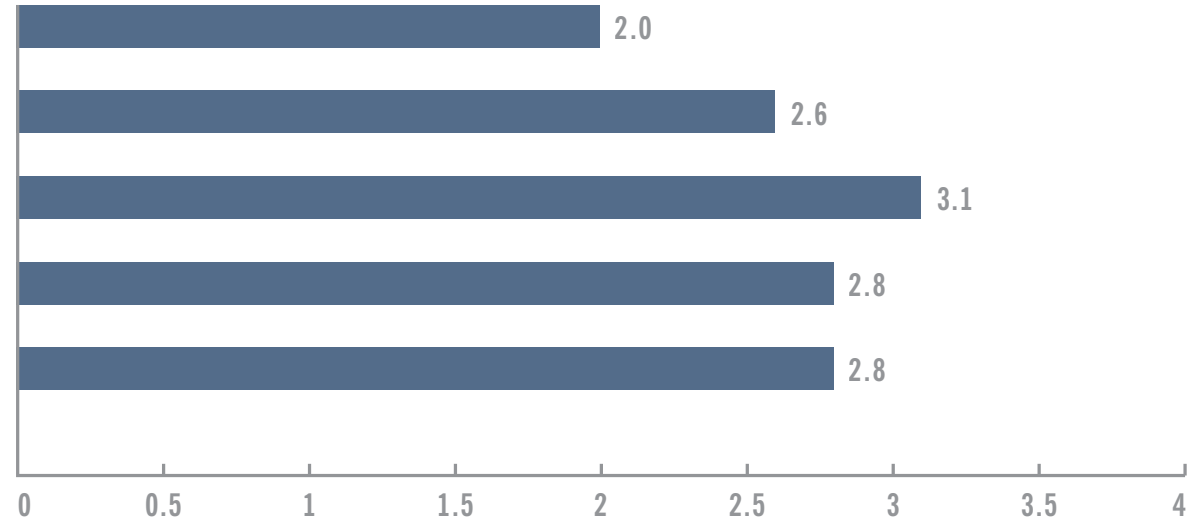

Note: $\uparrow$ Several questions are adapted from the National Survey of Student Engagement. We have obtained permission to use these questions. 


\section{Appendix C: More Detail on Cost Analysis}

Instructors for the treatment sections and case studies were asked to complete summer time sheets documenting the amount of time they spent preparing for the class. This included time spent reviewing and selecting content, learning how to use the online platform, designing the features of the course, and working through technology issues. Twelve faculty members, from 10 courses, submitted these data. ${ }^{23}$ We also asked instructors to estimate how much of this work would need to be repeated if they taught the course again. During the fall semester, we asked instructors to complete a time sheet each week describing the amount of time they spent on the course and how it was broken down by categories related to delivering the course and preparing for the course. (Both time sheet tools are provided in Appendix E.) Instructors were given the option of providing these data in interviews at the middle and end of the semester, and two opted to do this instead of filling out timesheets. We were able to collect the fall data for 19 instructors, from 14 courses. During our final interviews we asked questions about the instructor's time allocations and the potential for time savings from using the technology. Instructors from three control sections also provided these data, but given that the control instructors did not volunteer to participate in this study, most were not willing to provide time use data.

Several of the instructors were resistant to providing these kinds of data because they felt they could not accurately measure their time and that it would not be valuable to compare to others. The numbers we report are only representative of the 12 faculty who submitted both summer and fall time sheets. (Faculty members appear to prepare for courses at different times so we did not want to make assumptions about how faculty who only submitted a fall time sheet spent their time preparing for the course over the summer. All instructors who submitted summer time sheets also submitted fall time sheets.) We acknowledge the limitations of these data, especially given the variance in faculty teaching methods and experience, but we also believe that these data can provide useful insights and serve as a baseline for future research.

We hoped to track additional inputs in the cost of a course, such as IT and administrative support, in order to understand the ripple effects of implementing these technologies on a campus. However, because technical support for MOOCs was provided by Coursera or through the University System of Maryland office, most instructors reported limited use of local IT support staff. Demands on administrators for the models we tested appeared to be minimal and primarily due to the research needs. Thus, given the isolated nature of most of these courses on the

23 Five of these are case studies and five are side-by-side tests. 
campus, it was difficult to estimate the larger institutional impact of the use of these technologies.

\section{Findings}

Faculty spent a substantial amount of time-with medians for different course types between 115 and 205 hours - redesigning their courses using technology (including time spent over the summer and during the fall). Roughly half of that time - an average of 81 hours - was spent during the summer surveying the possibilities for externally produced course content and making decisions about how to integrate that content into their courses. Other significant components of the summer work included learning to use the technology platform- 16 hours on average; designing the course delivery—18 hours; and setting up the online course components -14 hours. For many instructors, this work continued into the time the course is actually taught, with an average of 2.87 hours per week being spent on similar tasks through the fall.

The table below describes the averages and medians of time spent on course development over the summer and how this time was allocated to various activities.

Appendix Table 9: Time Spent Preparing for the Course During the Summer in Hours (12 instructors)

\begin{tabular}{|c|c|c|c|c|}
\hline & Average & Median & Min & Max \\
\hline Content Development & 81 & 40 & 16 & $400 \dagger$ \\
\hline $\begin{array}{l}\text { Designing the Course } \\
\text { Delivery }\end{array}$ & 18 & 8 & 1 & 80 \\
\hline $\begin{array}{l}\text { Learning to Use } \\
\text { Technology Platform }\end{array}$ & 16 & 11 & 4 & 40 \\
\hline IT Issues & 7 & 3 & 0 & 30 \\
\hline $\begin{array}{l}\text { Setting up Online } \\
\text { Course Components }\end{array}$ & 14 & 6 & 0 & 40 \\
\hline Administration & 2 & 0 & 0 & 10 \\
\hline $\begin{array}{l}\text { Meeting with TAs or } \\
\text { other instructors }\end{array}$ & 5 & 3 & 0 & 25 \\
\hline Other & 4 & 1 & 0 & 14 \\
\hline Total & 144 & 68 & 34 & $470 \dagger$ \\
\hline
\end{tabular}

Note: †This includes extensive time spent creating new content for the online platform.

We also separated the preparation time by whether the technology component was supplemental or a replacement for usual content (Appendix Table 10). One should note that these are very small samples, but the preparation time for supplemental courses does appear to be less. This makes sense, given that these instructors did not redesign the traditional version of their course to fit with the technology. Instead they only needed to review the supplemental tools and determine what to include. 
Appendix Table 10: Average Time Spent Preparing for the Course

During the Summer in Hours

\begin{tabular}{lll} 
& $\begin{array}{l}\text { Replacement } \\
(8 \text { instructors })\end{array}$ & $\begin{array}{l}\text { Supplemental } \\
\text { (4 instructors) }\end{array}$ \\
\hline Content Development & 94 & 33 \\
\hline Designing the Course Delivery & 21 & 7 \\
\hline Learning to Use Technology Platform & 17 & 10 \\
\hline IT Issues & 8 & 2 \\
\hline Setting up Online Course Components & 12 & 13 \\
\hline Administration & 1 & 13 \\
\hline Meeting with TAs or other instructors & 5 & 3 \\
\hline Other & 4 & 1 \\
\hline Total & 163 & 71
\end{tabular}

Appendix Table 11 describes the average weekly time spent delivering the course by the 19 instructors who submitted these data. Some instructors taught multiple sections, and delivery time (in-class time, student support and grading) is directly related to the number of sections an instructor taught. Thus, we divided average weekly delivery time for each instructor by the number of sections he or she taught. It is difficult to interpret these data, since we do not have traditional course data to compare them to, but they can provide rough estimates for faculty thinking about redesigning their courses with technology. We can also see that time spent supporting students is not extremely high, as some may have anticipated happening as a result of reduced face-to-face time. Grading time is lower for OLI courses than Coursera courses, but it may be more due to the types of assignments associated with biology (often times multiple choice exams), which can be easier to grade than the essays used in some of the MOOC-based courses. Finally, by design, the instructor's face-to-face time was less for the hybrid courses.

Appendix Table 11: Average Weekly Time Spent Delivering the Course Per Section

\begin{tabular}{|c|c|c|c|c|c|c|}
\hline & $\begin{array}{l}\text { Face-to-Face Class } \\
\text { Time }\end{array}$ & $\begin{array}{l}\text { Supporting } \\
\text { Individual Students }\end{array}$ & $\begin{array}{l}\text { Grading } \\
\text { Assignments }\end{array}$ & $\begin{array}{l}\text { Tweaking } \\
\text { Course Plan }\end{array}$ & Other & $\begin{array}{l}\text { Total } \\
\text { Time Spent }\end{array}$ \\
\hline All & 1.68 & 0.72 & 1.01 & 0.38 & 0.13 & 3.93 \\
\hline Case Studies & 1.96 & 0.43 & 1.12 & 0.70 & 0.21 & 4.42 \\
\hline Side By Side & 1.48 & 0.94 & 0.93 & 0.15 & 0.07 & 3.57 \\
\hline Supplemental & 1.97 & 1.78 & 1.35 & 0.16 & 0.09 & 5.34 \\
\hline Courses using OLI & 0.86 & 4.86 & 0.14 & 0.14 & 0.00 & 6.00 \\
\hline Courses using M00Cs & 1.85 & 0.50 & 1.08 & 0.40 & 0.11 & 3.93 \\
\hline
\end{tabular}

Notes: "Supporting Individual Students" includes answering questions from students outside of the classroom, and encompasses monitoring online forums, monitoring student usage of online materials, and interacting with students during office hours. "Tweaking Course Plan" includes rethinking and revising course design and course content. 


\title{
Appendix D: Descriptions of Case Studies
}

\author{
New Media: Installations and Public Art
}

Fall 2013

\section{Course Structure}

This art course is a small, upper level elective primarily composed of junior and senior art majors. The professor chose to incorporate the "Critical Thinking in Global Challenges" MOOC to enable students to spend more of their class time doing hands-on work in the studio while also strengthening the content component of the course. The students were required to incorporate elements of the MOOC content into their artwork and she hoped it would push them to think more deeply about their work. She saw improvements in students' critical thinking and mentioned that the emphasis on the research process was also helpful.

Students were assigned all components of the MOOC, including quizzes, assignments, homework and videos. They also integrated concepts from the MOOC into their designs for an art park. The course met for the same amount of time as usual, but the class time was used differently and students had to spend more time out of class on coursework. The instructor also hoped that by assigning the videos and quizzes, students would be forced to do more work outside of class than they have done in the past.

During most class sessions the instructor and her students discussed art and the research process. They completed three projects which were related to the MOOC. During the last five weeks they spent more time discussing the issues covered in the MOOC and focused on the final project, which was related to the full set of videos. The students participated well in these discussions and the professor mentioned that she thought students had better critical thinking skills in this course than usual. From her perspective, the students who are usually most engaged seemed to get the most out of this course and the addition of the MOOC content.

Student survey responses indicate that, on average, students felt that they learned more in this course than a usual lecture course. The average of their responses was four on a five point scale. For questions regarding whether they enjoyed using Coursera and how much they learned from Coursera, their responses were close to neutral. The professor mentioned that students complained that the MOOC was not integrated with the course very well; it seemed like a separate course. However, the students did not complain to the instructor about the workload. The professor had a great experience with the MOOC and would love to use it again. Overall she rated the experiment as a 7 on a scale from 1 to 10 , and she would like to develop and refine it more over coming semesters. She mentioned that the integration between Coursera and the LMS was one of the most difficult and time consuming parts of the course. If she taught it again, she would like to set up 
a more seamless integration between the MOOC and the LMS. She would also probably create some of her own videos. She felt that it was still important to maintain the face-to-face portion of the course because the students at her institution tend to apprehensive towards online learning. However, she saw the MOOC as a valuable resource because it provided high quality materials and minimized the need for her to find or create online content herself.

\section{Modern Poetry}

\section{Fall 2013}

This course is an upper level English elective meant primarily for English majors. It is usually a small course, and it enrolled 11 students in fall 2013. In this version, the students enrolled in the live version of the MOOC "Modern Poetry." The professor assigned most of the videos, and students were expected to complete most of the assignments associated with the MOOC, including the quizzes, papers, peer reviews and discussion boards. Students also submitted these assignments, as well as a few additional assignments and exams from the professor for extra credit.

The professor chose to use the MOOC because she wanted to increase students' critical thinking about poetry and expose them to a higher level of intellectual discourse than they typically experience in their courses. She incorporated ideas from the MOOC videos and discussions into their classroom discussions and encouraged students to build on others' perspectives. The class met for three, fiftyminute sessions per week, which is the same as its usual schedule.

The professor felt that the course was a success and she reported that students "loved the lecture videos." The MOOC provided a safe entry through which the students could approach poetry. They were able to build on the videotaped discussions, and by the middle of the course they knew how to participate, were not afraid to comment and were making connections between the poems. The professor recorded a few of their in-class discussions as well, and students liked this opportunity to emulate what they were watching in the MOOC. Some elements of the global community of the MOOC were overwhelming for the students. They participated in the discussion forums and peer review but the discussion forums were difficult to navigate and some students mentioned that they preferred more direct feedback than was provided through peer review. Traversing between Coursera and Blackboard was another concern for the students. However, the professor mentioned that the online discussion forums helped students to engage more deeply in their in-class sessions and she appreciated how the in-class time enabled them to engage with the online materials.

The professor also mentioned that teaching with the MOOC was a great learning experience for her. It gave her insight into teaching methods that she will take into her classes and she would love to teach with a MOOC again. It saved her time in terms of deciding what content to include and she mentioned that this would be a great tool if she was teaching a class for the first time. 


\section{Introduction to Genetics}

\section{Fall 2013}

This is a required course for students majoring in biology. The course is usually taken in the sophomore or junior year after students have taken the prerequisite introductory biology course. Two sections are offered, but only one, with 59 students, participated in the study. The course typically meets twice a week for 75 minutes each time. The professor redesigned the course a few times in order to incorporate online materials, usually from a publisher, in attempt to improve student outcomes. One of the professor's goals for this study was to determine whether or not student engagement and outcomes would improve when he used the "Introduction to Genetics and Evolution" MOOC in their course. The course typically has a high DFW (drop, failure or withdrawal) rate, around 40 percent. The professor plans to administer some of the same exam questions from fall 2013 in a future instance of the traditional version of the course in order to compare student outcomes.

The professor put together groups of lecture videos, usually three videos, to replace some of the class periods. This happened at most once a week, and during these weeks the students were expected to watch the videos and complete the quiz and homework assignments related to the MOOC. The professor created all of these assignments and did not use any of the ones from the MOOC because he thought they were too easy. The MOOC work was designed to take as much time as a usual class period, and students could choose to complete this in the computer lab during the usual class time and where a TA was available, or at home. In the lecture period following the video assignment, the class would discuss the MOOC and the professor would highlight the important parts of the video and assignments.

The MOOC covered topics that the professor had not previously covered in this course, so it forced him to restructure his course and redirect some of the content. He thinks the students enjoyed the videos, and for the students who submitted surveys (roughly half), the average rating of the educational value of the lecture videos was 3.9 on a five point scale. The TA thought that a lot of the material was better suited to a higher level course, and although the professor worked hard to identify the most appropriate videos, they still seemed to be difficult for students, who gave an average rating of $3.8 / 5$ for course difficulty. Students' average rating of the course was $3.2 / 5$, and the average rating of how much they learned compared to other courses of the same level was 3.7/5.

Student performance appeared similar to previous instances of the course. The DFW rate was $41 \%$, which is within the normal range, and other indicators of student performance appeared similar. However, the professor did not have any tools to make direct comparisons to other instances of the course.

The professor enjoyed teaching with the MOOC because it was fun for him to see how he could restate or elaborate on the MOOC materials, and he enjoyed the lectures he was using. It did not save him any time; he had to spend extra time developing the course, which offset the time he saved by not lecturing some weeks. He could see it saving him some time in future instances, and the MOOC was helpful in guiding the content to include in the course, which could reduce time in developing content. He also appreciated that it enabled him to "flip the 
classroom" (meaning that he used class time for discussion rather than lecturing), and if he taught with the MOOC again he would take more advantage of the flipped classroom model.

\section{Learning Community: Train Your Brain}

\section{Fall 2013}

All first-year students at this university are required to enroll in a learning community during their fall semester. These are usually groups of two to three courses with a related theme and an orientation component to help students adjust to the university. The Psychology department offered this new learning community,Train Your Brain, which incorporated the MOOC "Nutrition, Health, and Lifestyle: Issues and Insights" into its three courses: Health in America, General Psychology and the orientation course. The professor chose to use this MOOC because it covers two of the five themes for this learning community and it is rare to find materials that cover more than one area. She also felt that the MOOC helped connect the different areas in a way that would be helpful to students.

The MOOC videos were primarily used in the Health in America and orientation courses and their main purpose was to reinforce or replace the course content. There were three periods in the semester during which students worked on the MOOC. Students were meant to take the MOOC quizzes to demonstrate that they viewed the video, and the professor adapted the MOOC project to fit with their class. The MOOC material was also covered in the exam for one of the courses. One of the goals of the course was to have students track their own exercise and nutrition; however the implementation of this part was incorrectly communicated and, as a result, they were prevented from including this measure. Another goal of the course was to have a high retention rate, and they ended up with about the same retention rate as the other learning communities.

The use of the MOOC in this learning community created flipped classroom environments whereby students were expected to learn content independently, while class time was used for more engaging activities. As a result, instructors were able to cover topics more quickly, and class time focused on discussion of concepts and how they apply to students' lives. Students were engaged and they liked the videos but the professor did not notice anything outstanding or different than usual.

They would like to use the MOOC again in the fall of 2014 and they believe they could improve upon the course. They would incorporate the MOOC in the orientation course every week if they used it again, instead of in three separate periods during the semester. The professor mentioned that the MOOC was a great teaching resource because it enabled instructors to view a class differently and come out of their own little world.

This MOOC was a good fit for the course. It helped apply the content to the students' lives, and the students liked that the materials seemed more personalized than publisher materials because the MOOC professor was speaking directly to them. The professor mentioned that the students found the videos to be interesting and helpful, however their survey responses indicated an average rating of $2.4 / 5$ for the educational value of the lecture videos. Their average was higher, 
3.4/5, for the scale of "Using Coursera made this course more enjoyable than a normal face-to-face course" and $3.5 / 5$ for "I felt that I learned a great deal from Coursera."

\section{Human Computer Interaction}

\section{Fall 2013}

Human Computer Interaction is an upper level course in the Computer Science and Information Technology department. It is an elective for seniors majoring in computer science or information systems, and it is a requirement for those majoring in information technology. The course primarily consists of seniors, and 25 students enrolled in the course (we only have grades for 19). The "Design: Creation of Artifacts in Society" MOOC was used for the middle third of the class. During these six weeks, students watched the MOOC videos at home, completed the supplemental readings and took quizzes that the professor created to ensure that students were completing this work. The course project also incorporated parts of the project associated with the MOOC and the content of the MOOC was covered in the second exam. Students attended class once every two weeks during the MOOC period, and the rest of the semester they attended according to their usual class schedule.

The professor chose to use the MOOC because it provided greater depth on a subject than she usually covers. She also thought the format would encourage greater engagement than the usual lectures because it forces more student participation. Her specialty is in a field other than human computer interaction, so she appreciated that the MOOC was able to provide more expertise and better examples than she usually does. She also mentioned that she learned a lot from using the MOOC and had fun with it.

There were some discrepancies between the MOOC and the course subject, and the professor was disappointed that there were no reading assignments available with it. However, she did mention that it was the appropriate level for students. She is also concerned that students may not have remembered the material as well from watching videos as they would from lectures because they did not all take notes, and the MOOC does not reiterate and emphasize important content in the same way that she does in her lectures. If she taught with the MOOC again, she would require students to take notes while watching the videos, and would encourage them to watch the videos multiple times. She also mentioned that she taught most of these students in her other classes and it was helpful that she saw them during the MOOC weeks even though they did not meet for this class.

The professor stated that she would use the MOOC again if it seemed that the students like it. Only 11 of the students submitted surveys, but among these students, the average rating for how much they learned in the course was $3.5 / 5$ and the average rating of the educational value lecture videos was $4.3 / 5$ - the highest rating given to any component of any course. All of the average ratings from the surveys were either positive or neutral, so it appears that the students did enjoy the course. It is also worth noting that this professor is the only full time faculty member in her department, so her students often have four or five courses with her. In this 
context, one can imagine students benefitting from additional perspectives or expertise.

\section{Introduction to Comparative Politics}

\section{Fall 2013}

Introduction to Comparative Politics is mostly composed of first-year students and sophomores taking the course for a general education requirement. It is a small course, with 20 students initially enrolled; only 13 students completed the course.

The professor chose to incorporate the MOOC "Generating the Wealth of Nations" into his course because he saw it as an opportunity to increase student engagement and students' understanding of the economic concepts related to the course. Many students enter the course without a good understanding of macroeconomics, so the professor intended to use the MOOC to teach these principles in order to provide a good foundation for the course topics. The MOOC was used as a supplement for the usual class. The class met for 75 minutes twice a week. Each week one session was a lecture on course material and the other session was split between lecturing and discussions or activities related to the MOOC. The professor also created some of his own videos to incorporate in the class.

Most of the MOOC lectures are approximately twenty minutes long and they focus on broad critical thought questions. The professor hoped that these would reinforce the content students learn in class and in the textbook. He assigned a quiz with each video to test whether or not students are watching the videos, and he incorporated the MOOCs into group projects.

The professor liked the quality of the MOOCs and the level was appropriate for his students. However, the content was not adequately aligned with his course, which created some issues. The students were not convinced of the value of the MOOCs because it was difficult to see the connection between the MOOCs and the course content. The MOOC organized concepts differently than the professor does in his course, which made it difficult to align the materials. In addition, he wanted students to learn some of the MOOC content before it was covered in class so they would have the context to understand the class materials, but students did not understand or care about this need for preparedness and forward thinking. The professor designed activities to help students understand the role of the videos in the overall course structure and students did not seem to complain that they were not relevant. However, he would expect better participation and engagement if he used more closely aligned videos.

The professor hoped that students would be more likely to watch the MOOC videos than they were to read the textbook, since he has traditionally struggled to get students to complete readings. However, students did not appear more likely to watch the videos, nor did they seem to retain the information better or participate more in class. Only ten of the students opened the videos, but he does not know how many of the students actually watched the videos and if they watched them in full or in part. A handful of students seemed more engaged in the course than usual; however, this did not translate to the class as a whole. 
The professor is creating his own videos which are more directly related to the course. Although he has not been able to find other good online comparative politics materials, he is still open to using others' materials if they fit well with the course.

\section{Learning Community: Opinions are Like Belly Buttons}

\section{Fall 2013}

All first-year students at this university are required to enroll in a learning community during their fall semester. This three course learning community included "Introduction to Literature," the "First Year Seminar: An Introduction to University Learning," and "Information Literacy." One professor taught the first two courses and another professor taught "Information Literacy." Each of the courses was linked to the MOOC "Think Again: To Reason and Argue," though they each incorporated it in a slightly different way. There was a student assistant who coached the students through each of these courses, as well as through the weekly session where students viewed the MOOC and completed MOOC-related exercises together. In addition to this weekly MOOC session, each of the courses met once a week.

The literature course used the MOOC to help students learn about the structure of arguments. Students have traditionally struggled with creating strong arguments or understanding what makes a good argument, as well as with how to use evidence appropriately. The MOOC addresses argumentation theory, and students practiced evaluating and creating arguments with evidence by applying these skills to literature and writing essays. This course included weekly argument outlines, three argument essays, weekly online discussions, an author essay and a final project. Another purpose of the MOOC was to create a common experience to which all students could relate. Students do not come to these courses with a common understanding of literature, so the MOOC helped to set a foundation upon which they could build.

Introduction to University Learning used the MOOC as a tool to help students develop important critical thinking skills. The course focused on how to organize thoughts, relate to other people, ask questions and complete coursework effectively. Assessments for this course include quizzes, planning exercises, portfolio projects, online work related to the MOOC, participation and a final project. The online component of the course was set up to reinforce habits they were trying to instill in students. The work of the student tutor was focused on coaching students on these habits and practices. For example, she met with them to watch videos together and then talked with students about what points were important to remember and how to take good notes.

The professor of these two courses thought students did very well with this model. She said that the papers were far better than any other freshman course she has taught, and this was the best case of students providing specific evidence in the oral final. She thinks part of the benefit came from having a student tutor who was very engaged with the students. She also mentioned that students did not completely understand the purpose of integrating the MOOC in all three courses. They had more trouble seeing the connection between the MOOC and 
the information literacy course than the other two courses. Of the 12 students who submitted surveys, their average rating of how much they learned was $3.4 / 5$ and their average rating of the educational value of the lecture videos was also $3.4 / 5$.

The Information Literacy course used the MOOC to teach students to determine which sources are valid and how to appropriately use sources. A key goal of the course was to see if students could identify arguments and incorporate them into their assignments. Their assignments included an annotated bibliography, delivering a presentation on the value of different library resources for different research goals, and submitting a new version of an incomplete Wikipedia article. The professor found that it took students longer to process the MOOC than he expected. As a result, he had to cut back on some of the MOOC content they covered in class. He also thought that they did not need to go as deep into the MOOC as they did because some of the content did not align with his course as much as he would have liked. If he were to teach with the MOOC again he would use less of it. $\mathrm{He}$ also thought that meeting once a week was not sufficient, and he would have liked to have been present in the sessions where students worked on the MOOC so he would have a better understanding of how they connected with it.

\section{Wells of the Past: Classical Foundations}

\section{Fall 2013}

This is an upper level English course which usually enrolls older and working students. Seventeen students enrolled in this evening course in fall 2013. The instructor chose to incorporate a MOOC into his course to make the course more engaging and to improve upon some of the materials he traditionally uses. He incorporated the MOOCs "Ancient Greeks" and "Greek and Roman Mythology.” Students were required to view videos prior to discussions and to incorporate information from the lecture videos into their project work, which was theme-based. As part of the assessment of the projects, students were graded on whether or not they watched the video. They were not assigned other work from the MOOC.

The instructor found the MOOCs to be "brilliant" because they provided information that he would normally need to pull from multiple sources, and the students found them engaging and helpful. He also noted that the MOOCs made it easier for students to form connections between the literature and archeological record, and it made the ancient world come more alive. The course is primarily project and discussion based, and the instructor thought that this format facilitated an easier incorporation of the MOOCs. The instructor noted that students came to class far more prepared after viewing the lectures than they do after only completing technical readings from textbooks. They were better able to complete the homework, and they maintained the high quality of discussion for which his classes are noted.

Overall the instructor was very positive about his experience teaching with the MOOCs and would be happy to use them again. The 10 student surveys indicate a positive experience as well. The average rating of this course compared to a typical lecture course was $4.2 / 5$ and the average rating of the educational value of the lecture videos was $4.2 / 5$. 


\section{Fall 2013}

This course was part of a freshman learning community. All first-year students at this university are required to enroll in a two- or three-course learning community to help introduce them to the university and prepare them to be students. This was a literature course focused on understanding a series of Irish plays and dramaturgical elements. The course met once a week for two and a half hours and most in-class time was spent on discussions and interactive activities. Students were assigned MOOC videos from Think Again: How to Reason and Argue to watch out of class. The MOOC was intended to support the topics discussed in class and those read in the plays. The discussions and three course projects incorporated the MOOC.

Due to factors unrelated to the study, the instructor reported numerous problems with the course. The student ratings of the course and MOOCs were close to neutral. Their average rating of how much they learned was 2.8 on a 5 point scale, their average overall rating of the course was 3.3 and their average rating of the lecture videos was 2.9.

\section{Introduction to Philosophy}

\section{Summer 2013}

Introduction to Philosophy is offered as a four-week summer course entirely online. It is typically a small class, and six students enrolled for this term. In the past, the course was constructed of readings, discussion boards, essay assignments, short video clips and online activities. She believed that the course would be more engaging with lecture videos but did not have time to create these herself. To solve this problem, the professor redesigned it using the "Introduction to Philosophy" MOOC as the primary content. She assembled her own set of readings to accompany these lectures and added questions related to these readings to some of the pre-existing MOOC quizzes. Essay assignments were graded both by her and using the MOOC peer review feature, which counted for a small percentage of the grade. The peer review process was valuable for the students because they were exposed to other perspectives; however the professor felt it was necessary for her to grade the essays as well because she focused on different elements than the students did.

The student surveys indicated positive reviews of the MOOC materials. They enjoyed the videos, peer reviews and format of the course. The feedback on how much they learned and the difficulty of the course was mixed. However, there were only five student surveys, so it is difficult to gauge much about the student perspective from the average ratings. The professor reported that she had a positive experience with the course. She would be interested in teaching the course again and thinks that other professors may benefit from this type of model. 


\section{Appendix E: Study Instruments}

\section{Cost Analysis Worksheet: Course Planning Time}

Please estimate the number of hours you spent on each category of activity during your course planning process up through the beginning of the fall semester.

[Note: these data are only going to be used by Ithaka $S+R$ researchers to learn about the costs involved in teaching with new online tools. They will NOT be used for any administrative purposes.]

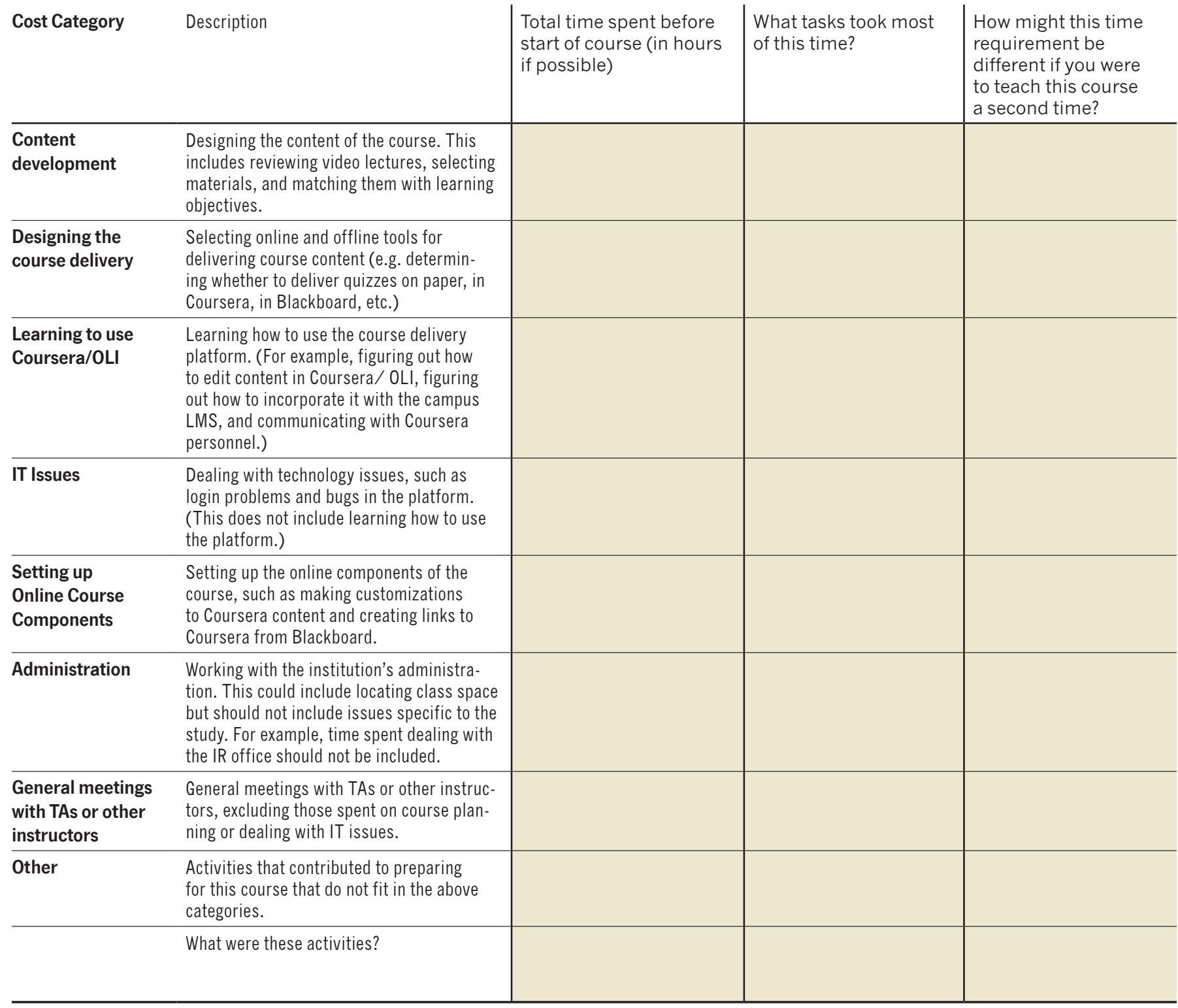




\section{Weekly Time Allocation Estimates}

Please enter the number of hours you spent each week on various activities.

Getting an accurate total for each week is more important than the precise breakdown. Please note any unusual circumstances in the "Notes" column for each week, such as reasons for spending an unusually large amount of time on a particular activity.

\begin{tabular}{|c|c|c|c|c|c|}
\hline Category & Explanation & Week 1 & Notes & Week 2 & Notes \\
\hline \multicolumn{6}{|l|}{ Course Delivery } \\
\hline $\begin{array}{l}\text { Face-to-Face Class } \\
\text { Time }\end{array}$ & Teaching face-to-face classes & & & & \\
\hline $\begin{array}{l}\text { Supporting } \\
\text { Individual Students }\end{array}$ & $\begin{array}{l}\text { Answering questions from students } \\
\text { outside of the classroom. This includes } \\
\text { monitoring online forums, monitoring } \\
\text { student usage of online materials, and } \\
\text { interacting with students during office } \\
\text { hours. }\end{array}$ & & & & \\
\hline $\begin{array}{l}\text { Grading } \\
\text { Assignments }\end{array}$ & $\begin{array}{l}\text { Grading assessments, quizess, home- } \\
\text { work, exams etc. }\end{array}$ & & & & \\
\hline $\begin{array}{l}\text { Tweaking } \\
\text { Course Plan }\end{array}$ & $\begin{array}{l}\text { Rethinking and revising course design } \\
\text { and course content. }\end{array}$ & & & & \\
\hline Other & $\begin{array}{l}\text { Resources that went into delivering this } \\
\text { course that do not fit into the above } \\
\text { categories. (Please note what these } \\
\text { activities were) }\end{array}$ & & & & \\
\hline $\begin{array}{l}\text { TOTAL TIME } \\
\text { SPENT }\end{array}$ & & & & & \\
\hline
\end{tabular}

\section{Course Preparation}

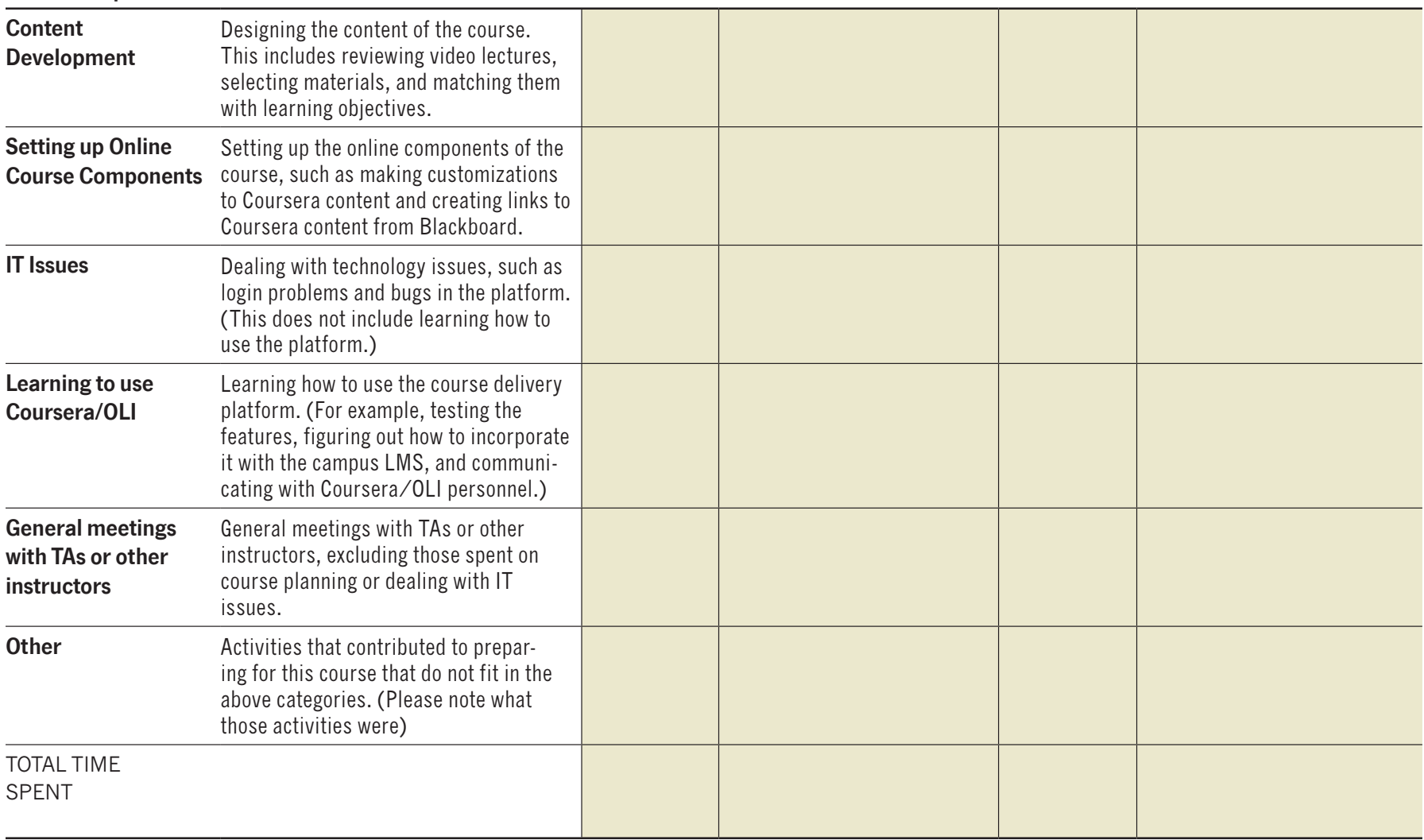




\section{Final Faculty Interview Questions}

\section{Faculty experience and attitudes}

1. Before you began teaching this course you told me how you planned to do it. Did you end up doing this course the way you thought you would or did you make significant changes to those plans? [Probe for significant changes.]

2. Did you use the entire MOOC as-is or in bits and pieces? If bits and pieces, what did you use and how did you use those things?

3. What features of the platform did you use? [Prompt for what they thought of the features they used.] How would you rate them?]

4. What parts of the course went well and what parts did not go so well?

5. Did you teach this class differently than you did before specifically because you had the MOOC materials and the platform features to work with? How did you change the course? [Prompt for use of class time, pacing of the course, treatment of content itself.] How do you feel about making those changes?

6. Did you get satisfaction and enjoyment out of teaching with this MOOC? How did it compare to teaching the course without a MOOC with regard to your personal satisfaction with the teaching itself? How did you feel about using material developed or presented by other experts?

7. What did you think of the quality of the content and its appropriateness for your class?

8. Can you compare this MOOC to other online tools, such as online publisher materials?

\section{Student experience and performance (in the opinion of this faculty member)}

9. With regard to your students, how was your interaction with students? How about your students' engagement with the material? As your students were using the MOOC materials, did you still feel that they respected your expertise and authority?

10. What is your perception of how well students learned the material in this format? What are you basing this assessment on?

11. Did you track students' use of the online resources, such as whether or not they watched the videos?

\section{Time spent and costs}

12. Questions specific to individual time sheet (Rebecca and Christine will review the timesheet before each interview.)

13. Were there parts of the work you did in this course that you think would have been pretty much the same even if there had been many more students in the course? (e.g. selecting the videos or student exercise and uploading them) What were these parts? Were there other parts of the work that varied pretty much directly with the number of students? (e.g. answering email questions or reading papers) Can you give examples of these types? Can you estimate what fraction of the total work fell in each category? 
14. Were any parts of the research process captured in your timesheet?

If so where and how much? We are trying to capture time spent on teachingnot time spent to help us study it.

15. With what precision did you record your time? Did you round to the nearest hour, half hour etc. How frequently did you fill out the time logs? Did you do it every week or did you go back and estimate a lot of the weeks?

16. Who else was involved in the course? TAs, course coordinator etc. Did you have any assistance from support staff, such as IT? What did each of these groups/individuals do? How much time did they spend? For the categories you left blank in the time sheet, did someone else complete those activities?

17. With regard for how much time it took for you to teach with the MOOC, what is your feeling - was this very demanding? [Note their reported totals and probe for how well their perception lines up with what they reported.] In teaching with a MOOC, did you allocate your time pretty much the same as a traditional course? [If not, probe for the differences.]

18. If you teach with the MOOC again, do you expect that the demands on your time will be more, less or the same? What work was primarily due to this being the first instance of the course?

\section{Overall assessment of the MOOC}

19. What did you hope to achieve in teaching this course? Did that change during the semester? Did you achieve what you had hoped? Did you achieve other things that you did not anticipate?

20. What would you do differently if you used the MOOC again?

21. How are you going to decide whether or not to use the MOOC again? [Prompt for the various factors they will consider, such as time demands, student response, satisfaction with that act of teaching, and so on.]

\section{Future of MOOCs}

22. Based on you experience and looking toward the future, what do you think are the worst aspects of MOOCs and what do you think is the greatest potential? Does anything about MOOCs scare you? Does anything about MOOCs excite you?

23. Do you think other faculty members could successfully use MOOCs? Do you think your department should put resources into moving forward with MOOCs? 


\section{Faculty Background questions}

1. How many years of teaching experience do you have at the college level (including your experience in teaching fall 2013)?

2. Are you a part time or full-time instructor?

3. What other courses, if any, did you teach in fall 2013?

4. What academic responsibilities, if any, did you have in fall 2013 outside of teaching this course?

5. How many times have you taught this course (including fall 2013) (at any institution)?

6. How many times have you taught this particular course, at this institution (including fall 2013)?

7. Have you previously taught a course that incorporates online technology?

8. Which of the following best describes your academic rank during the fall 2013 semester?

Professor

Associate Professor (with tenure)

Associate Professor (without tenure)

Assistant Professor

Lecturer

Adjunct

Graduate assistant

Other

9. How many sections of this course did you teach this semester? How many were treatment sections and how many were control sections?

10. How long did the face-to-face sessions usually last and how many times per week did you meet?

11. Is the format of this course determined by the instructor or the department? 


\section{Student Background Administrative Data Collected}

1. Student ID number that can be used to link records from various sources (random ID number created for the purposes of the project)

2. Month and year of birth

3. SAT verbal and math scores or ACT scores (if available)

4. Placement test scores (if available)

5. Race/ethnicity

6. Gender

7. Total number of credits earned as of beginning of semester in which study takes place

8. Cumulative college GPA as of beginning of semester in which study takes place

9. Is the student a full time or part time student during the current semester (fall 2013)

10. High school GPA

11. Family income (only available for students that completed a FAFSA)

12. Whether student matriculated as a freshmen or transfer student

13. Date of matriculation

14. Zip code at time of application

\section{Initial Survey}

Please answer the following questions to the best of your ability. If you do not feel comfortable answering a question, you may skip it.

1. Which of the following best describes your experience with [COURSE SUBJECT]? Please check one of the following:

I have never taken a course in this subject.

I learned a little about this subject as part of another course.

I took a whole course in this subject in high school but nothing in college.

I took a whole college-level course in this subject.

Other (please specify):

2. Which of the following best describes your reason for enrolling in [COURSE NAME]? Please check one of the following:

It is a requirement for my major

It satisfies other requirements for graduation

I chose this as elective.

Other (please specify): 
3. Do you own a computer or tablet? Please check all applicable answers:

No

Yes, a desktop

Yes, a laptop

Yes, tablet

4. Do you have reliable internet access where you live? Please check one:

Yes

No

5. Overall, how much time do you expect to spend on course work EACH week for ALL of your courses outside of class? Please check one of the following:

None

Less than 1 hour

$1-5$ hours

6-10 hours

11-15 hours

16-20 hours

Over 20 hours

6. How difficult do you expect this course to be? Please check one of the following:

Very easy

Easy

Moderate

Difficult

Very difficult

7. What is the highest level of education you expect to complete in the future? Please check one of the following:

Obtain a Bachelor's degree

Obtain a Master's degree or equivalent

Obtain a Ph.D., M.D., or other advanced or professional degree

Don't know

8. How many hours do you plan to work for pay (either on-campus or off-campus) this semester? Please check one of the following:

I do not plan to work

I plan to work 1-9 hours each week

I plan to work 10-19 hours each week

I plan to work 20-29 hours each week

I plan to work 30-39 hours each week

I plan to work 40 or more hours each week 
9. Where do you live? Please check one of the following:

On-campus housing

I live with parent(s) or other guardian(s)

I live independently (alone, with my own family, or with roommates)

10. Please indicate the highest level of education completed by your

Father (or parent/guardian \#1): $\quad$ Mother (or parent/guardian \#2):

(Please check one of the following.)

Did not complete high school

Did not complete high school

High school diploma or equivalent

High school diploma or equivalent

Some college

Some college

Bachelor's or four-year degree

Bachelor's or four-year degree

Graduate or professional degree

Graduate or professional degree

Don't know

Don't know

11. What is the approximate combined income of your parents before taxes?

(Please check one of the following.)

Less than $\$ 50,000$

$\$ 50,000$ to $\$ 100,000$

$\$ 100,000$ to $\$ 200,000$

More than $\$ 200,000$

Don't know

12. Are you married?

Yes

No

13. Do you have children or other dependants?

Yes

No

14. What language do you know best? (Please choose one of the following.)

English

English and another language about the same

Another language

15. What month were you born?

16. What year were you born?

17. What is your gender? (Please check one)

male

female 


\section{Final Survey for Control Sections}

Please answer the following questions to the best of your ability. If you do not feel comfortable answering a question, you may skip it.

On average, how many hours per week did you spend on coursework for this course outside of the face-to-face classroom meetings?

hours per week

How much did [COURSE NAME] increase your interest in the subject matter? (Please check one of the following.)
not at all
very little
some
quite a bit
a great deal

How much did you learn in this course compared to other courses of the same level? (Please check one of the following.)

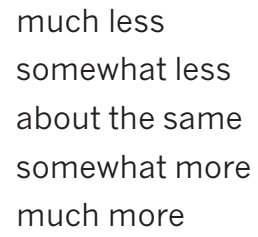

Overall, how would you rate this course relative to a typical lecture-based course? (Please check one of the following.)
much worse
somewhat worse
about the same
somewhat better
much better

How difficult did you find [COURSE NAME]? (Please check one of the following.)
very easy
easy
moderate
difficult
very difficult 
On a scale from 1 (lowest) to 5 (highest) please rate the educational value of the following aspects of the course. Please check one box in each row.

\begin{tabular}{l|l|l|l|l|l} 
& 1 & 2 & 3 & 4 & 5 \\
$\begin{array}{l}\text { In-class activities } \\
\text { Homework assignments } \\
\text { Textbook } \\
\text { Office hours } \\
\text { Lecture videos } \\
\text { Online discussion forums } \\
\text { Online problem sets } \\
\text { Online quizzes } \\
\text { Exams }\end{array}$ & & & & & \\
\end{tabular}

Approximately what percentage of the face-to-face classroom meetings did you attend?

$\%$

For those face-to-face classroom meetings you did attend, please rate, on a scale from 1 (not at all important) to 5 (very important), the importance of each factor below in your decision to attend. Please check one box in each row.

\begin{tabular}{|c|c|c|c|c|c|c|}
\hline & 1 & 2 & 3 & 4 & 5 & $\mathrm{n} / \mathrm{a}$ \\
\hline \multicolumn{7}{|l|}{$\begin{array}{l}\text { Attendance was part of my } \\
\text { grade }\end{array}$} \\
\hline \multicolumn{7}{|l|}{$\begin{array}{l}\text { My instructor's explanations } \\
\text { of the material }\end{array}$} \\
\hline \multicolumn{7}{|l|}{$\begin{array}{l}\text { Getting answers to specific } \\
\text { questions I had about the } \\
\text { course }\end{array}$} \\
\hline \multicolumn{7}{|l|}{$\begin{array}{l}\text { Going over practice or home- } \\
\text { work problems }\end{array}$} \\
\hline \multicolumn{7}{|l|}{$\begin{array}{l}\text { Engaging in class } \\
\text { discussions }\end{array}$} \\
\hline \multicolumn{7}{|l|}{$\begin{array}{l}\text { Reviewing for midterms or } \\
\text { final exams }\end{array}$} \\
\hline \multicolumn{7}{|l|}{$\begin{array}{l}\text { Doing other activities } \\
\text { (specify below in comments } \\
\text { section) }\end{array}$} \\
\hline $\begin{array}{l}\text { OVERALL value of the face- } \\
\text { to-face sessions in helping } \\
\text { you understand the course } \\
\text { material }\end{array}$ & & & & & & \\
\hline
\end{tabular}


During this course, about how often have you done the following?*

\begin{tabular}{l|l|l|l|l} 
& $\begin{array}{l}\text { Very often } \\
\text { (multiple } \\
\text { times per } \\
\text { week) }\end{array}$ & $\begin{array}{l}\text { Often (one } \\
\text { every week } \\
\text { or two) }\end{array}$ & $\begin{array}{l}\text { Sometimes } \\
\text { (a few times } \\
\text { during the } \\
\text { semester) }\end{array}$ & Never \\
$\begin{array}{l}\text { Asked questions or contrib- } \\
\text { uted to course discussions in } \\
\text { other ways }\end{array}$ & & \\
$\begin{array}{l}\text { Come to class without } \\
\text { completing readings or } \\
\text { assignments }\end{array}$ & \\
$\begin{array}{l}\text { Asked another student to } \\
\text { help you understand course } \\
\text { material }\end{array}$ & \\
$\begin{array}{l}\text { Explained course material to } \\
\text { one or more students }\end{array}$ & \\
$\begin{array}{l}\text { Worked with other stu- } \\
\text { dents on course projects or } \\
\text { assignments } \\
\text { Connected your learning to } \\
\text { societal problems or issues }\end{array}$ & & \\
$\begin{array}{l}\text { Connected ideas from your } \\
\text { courses to prior experience } \\
\text { or things you have learned in } \\
\text { other courses }\end{array}$ & & & \\
& & \\
& & \\
\end{tabular}

During this course, how much has your coursework emphasized the following?*

\begin{tabular}{l|l|l|l|l} 
& $\begin{array}{l}\text { Very often } \\
\text { (multiple } \\
\text { times per } \\
\text { week) }\end{array}$ & $\begin{array}{l}\text { Often (one } \\
\text { every week } \\
\text { or two) }\end{array}$ & $\begin{array}{l}\text { Sometimes } \\
\text { (a few times } \\
\text { during the } \\
\text { semester) }\end{array}$ & Never \\
$\begin{array}{l}\text { Memorizing course material } \\
\begin{array}{l}\text { Applying facts, theories, or } \\
\text { methods to practical prob- } \\
\text { lems or new situations }\end{array}\end{array}$ & & \\
$\begin{array}{l}\text { Analyzing an idea, experi- } \\
\text { ence or line of reasoning in } \\
\text { depth by examining its parts }\end{array}$ & & \\
$\begin{array}{l}\text { Evaluating a point of view, } \\
\text { decision, or information } \\
\text { source }\end{array}$ & & \\
$\begin{array}{l}\text { Forming a new idea or } \\
\text { understanding from various } \\
\text { pieces of information }\end{array}$ & & & \\
\hline
\end{tabular}

What features of the course do you feel could be improved? 
Do you have any other comments you would like to share about [COURSE NAME]?

*These questions were adapted from the National Survey of Student

Engagements. We have obtained permission from Indiana University to use these questions. 


\section{Final Survey - Treatment Sections}

Please answer the following questions to the best of your ability. If you do not feel comfortable answering a question, you may skip it.

On average, how many hours per week did you spend on coursework for this course outside of the weekly face-to-face classroom meetings?

hours per week

How much did [COURSE NAME] increase your interest in the subject matter? (Please check one of the following.)
not at all
very little
some
quite a bit
a great deal

How much did you learn in this course compared to other courses of the same level? (Please check one of the following.)

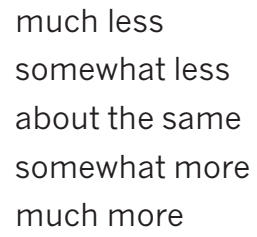

Overall, how would you rate this course relative to a typical lecture-based course? (Please check one of the following.)
much worse
somewhat worse
about the same
somewhat better
much better

How difficult did you find [COURSE NAME]? (Please check one of the following.)
very easy
easy
moderate
difficult
very difficult 
On a scale from 1 (lowest) to 5 (highest) please rate the educational value of the following aspects of the course? Please check one box in each row.

\begin{tabular}{l|l|l|l|l|l} 
& 1 & 2 & 3 & 4 & 5 \\
$\begin{array}{l}\text { Lecture videos } \\
\text { Online discussion forums } \\
\text { Online problem sets } \\
\text { Online quizzes } \\
\text { In-class activities } \\
\text { Homework assignments } \\
\text { Textbook } \\
\text { Office hours } \\
\text { Exams }\end{array}$ & & & & & \\
\end{tabular}

Approximately what percentage of the face-to-face classroom meetings did you attend?

$\%$

For those face-to-face classroom meetings you did attend, please rate, on a scale from 1 (not at all important) to 5 (very important), the importance of each factor below in your decision to attend. Please check one box in each row.

\begin{tabular}{|c|c|c|c|c|c|c|}
\hline & 1 & 2 & 3 & 4 & 5 & $\mathrm{n} / \mathrm{a}$ \\
\hline \multicolumn{7}{|l|}{$\begin{array}{l}\text { Attendance was part of my } \\
\text { grade }\end{array}$} \\
\hline \multicolumn{7}{|l|}{$\begin{array}{l}\text { My instructor's explanations } \\
\text { of the material }\end{array}$} \\
\hline \multicolumn{7}{|l|}{$\begin{array}{l}\text { Getting answers to specific } \\
\text { questions I had about the } \\
\text { course }\end{array}$} \\
\hline \multicolumn{7}{|l|}{$\begin{array}{l}\text { Going over practice or home- } \\
\text { work problems }\end{array}$} \\
\hline \multicolumn{7}{|l|}{$\begin{array}{l}\text { Engaging in class } \\
\text { discussions }\end{array}$} \\
\hline \multicolumn{7}{|l|}{$\begin{array}{l}\text { Reviewing for midterms or } \\
\text { final exams }\end{array}$} \\
\hline \multicolumn{7}{|l|}{$\begin{array}{l}\text { Doing other activities } \\
\text { (specify below in comments } \\
\text { section) }\end{array}$} \\
\hline $\begin{array}{l}\text { OVERALL value of the face- } \\
\text { to-face sessions in helping } \\
\text { you understand the course } \\
\text { material }\end{array}$ & & & & & & \\
\hline
\end{tabular}


During this course, about how often have you done the following?*

\begin{tabular}{|c|c|c|c|c|}
\hline & $\begin{array}{l}\text { Very often } \\
\text { (multiple } \\
\text { times per } \\
\text { week) }\end{array}$ & $\begin{array}{l}\text { Often (one } \\
\text { every week } \\
\text { or two) }\end{array}$ & $\begin{array}{l}\text { Sometimes } \\
\text { (a few times } \\
\text { during the } \\
\text { semester) }\end{array}$ & Never \\
\hline \multicolumn{5}{|l|}{$\begin{array}{l}\text { Asked questions or contrib- } \\
\text { uted to course discussions in } \\
\text { other ways }\end{array}$} \\
\hline \multicolumn{5}{|l|}{$\begin{array}{l}\text { Come to class without } \\
\text { completing readings or } \\
\text { assignments }\end{array}$} \\
\hline \multicolumn{5}{|l|}{$\begin{array}{l}\text { Asked another student to } \\
\text { help you understand course } \\
\text { material }\end{array}$} \\
\hline \multicolumn{5}{|l|}{$\begin{array}{l}\text { Explained course material to } \\
\text { one or more students }\end{array}$} \\
\hline \multicolumn{5}{|l|}{$\begin{array}{l}\text { Worked with other stu- } \\
\text { dents on course projects or } \\
\text { assignments }\end{array}$} \\
\hline \multicolumn{5}{|l|}{$\begin{array}{l}\text { Connected your learning to } \\
\text { societal problems or issues }\end{array}$} \\
\hline $\begin{array}{l}\text { Connected ideas from your } \\
\text { courses to prior experience } \\
\text { or things you have learned in } \\
\text { other courses }\end{array}$ & & & & \\
\hline
\end{tabular}

During this course, how much has your coursework emphasized the following?*

\begin{tabular}{l|l|l|l|l} 
& $\begin{array}{l}\text { Very often } \\
\text { (multiple } \\
\text { times per } \\
\text { week) }\end{array}$ & $\begin{array}{l}\text { Often (one } \\
\text { every week } \\
\text { or two) }\end{array}$ & $\begin{array}{l}\text { Sometimes } \\
\text { (a few times } \\
\text { during the } \\
\text { semester) }\end{array}$ & Never \\
$\begin{array}{l}\text { Memorizing course } \\
\text { material }\end{array}$ & & \\
$\begin{array}{l}\text { Applying facts, theories, or } \\
\text { methods to practical prob- } \\
\text { lems or new situations }\end{array}$ & \\
$\begin{array}{l}\text { Analyzing an idea, experi- } \\
\text { ence or line of reasoning in } \\
\text { depth by examining its parts } \\
\begin{array}{l}\text { Evaluating a point of view, } \\
\text { decision, or information } \\
\text { source }\end{array}\end{array}$ & \\
$\begin{array}{l}\text { Forming a new idea or } \\
\text { understanding from various } \\
\text { pieces of information }\end{array}$ & & \\
\hline
\end{tabular}


[FOR COURSERA TESTS ONLY] Please rate the extent to which you agree or disagree with the following statements:

\begin{tabular}{|c|c|c|c|c|c|}
\hline & $\begin{array}{l}\text { Strongly } \\
\text { disagree }\end{array}$ & Disagree & $\begin{array}{l}\text { Neither } \\
\text { agree nor } \\
\text { disagree }\end{array}$ & Agree & $\begin{array}{l}\text { Strongly } \\
\text { agree }\end{array}$ \\
\hline \multicolumn{6}{|l|}{$\begin{array}{l}\text { Using Coursera made } \\
\text { this course more } \\
\text { enjoyable than a } \\
\text { normal face-to-face } \\
\text { course }\end{array}$} \\
\hline \multicolumn{6}{|l|}{$\begin{array}{l}\text { The Coursera } \\
\text { materials seemed like } \\
\text { they were not meant } \\
\text { for me }\end{array}$} \\
\hline \multicolumn{6}{|l|}{$\begin{array}{l}\text { I felt that I learned } \\
\text { a great deal from } \\
\text { Coursera }\end{array}$} \\
\hline \multicolumn{6}{|l|}{$\begin{array}{l}\text { It was confusing } \\
\text { to have different } \\
\text { instructors teaching } \\
\text { the course online vs. } \\
\text { in-person }\end{array}$} \\
\hline \multicolumn{6}{|l|}{$\begin{array}{l}\text { It was hard to stay } \\
\text { motivated to do the } \\
\text { online work }\end{array}$} \\
\hline \multicolumn{6}{|l|}{$\begin{array}{l}\text { The Coursera materi- } \\
\text { als were engaging }\end{array}$} \\
\hline \multicolumn{6}{|l|}{$\begin{array}{l}\text { The Coursera materi- } \\
\text { als were high quality }\end{array}$} \\
\hline \multicolumn{6}{|l|}{$\begin{array}{l}\text { I found the Coursera } \\
\text { materials difficult to } \\
\text { follow }\end{array}$} \\
\hline $\begin{array}{l}\text { The Coursera materi- } \\
\text { als did not seem } \\
\text { appropriate for my } \\
\text { class }\end{array}$ & & & & & \\
\hline
\end{tabular}

The next set of questions is only for students who have taken other hybrid courses. Please rate the extent to which you agree or disagree with the following statements:

\begin{tabular}{|c|c|c|c|c|c|}
\hline & $\begin{array}{l}\text { Strongly } \\
\text { disagree }\end{array}$ & Disagree & $\begin{array}{l}\text { Neither } \\
\text { agree nor } \\
\text { disagree }\end{array}$ & Agree & $\begin{array}{l}\text { Strongly } \\
\text { agree }\end{array}$ \\
\hline $\begin{array}{l}\text { I enjoyed this course } \\
\text { more than other } \\
\text { hybrid courses I have } \\
\text { taken. }\end{array}$ & & & & & \\
\hline $\begin{array}{l}\text { I learned more from } \\
\text { this course than from } \\
\text { other hybrid courses }\end{array}$ & & & & & \\
\hline $\begin{array}{l}\text { The materials in } \\
\text { Coursera were higher } \\
\text { quality than those } \\
\text { used in other hybrid } \\
\text { courses I have taken. }\end{array}$ & & & & & \\
\hline $\begin{array}{l}\text { I prefer to use online } \\
\text { materials from pub- } \\
\text { lishers like Pearson } \\
\text { or McGraw Hill. }\end{array}$ & & & & & \\
\hline
\end{tabular}


How often did you have serious technical difficulties (e.g., server was down, page would not load after repeated attempts, a quiz would not work, etc.)? Please check one of the following:

Never

Once or twice

Often

Very often

If you had technical difficulties in the course could you please briefly describe the issues you encountered.

What features of the course do you feel could be improved?

Do you have any other comments you would like to share about [COURSE NAME]?

*Several questions are adapted from the National Survey of Student Engagement. We have obtained permission from Indiana University to use these questions. 
Final Survey - Case Study

Please answer the following questions to the best of your ability. If you do not feel comfortable answering a question, you may skip it.

How much did you learn in this course compared to other courses of the same level? (Please check one of the following.)
much less
somewhat less
about the same
somewhat more
much more

How much did you enjoy this course compared to other courses of the same level? (Please check one of the following.)
much less
somewhat less
about the same
somewhat more
much more

How difficult did you find [COURSE NAME] compared to other courses of the same level? (Please check one of the following.)

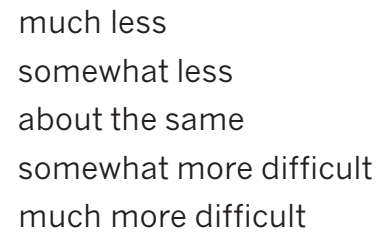

On a scale from 1 (lowest) to 5 (highest), what was the educational value of the following aspects of the course? Please check one box in each row.

\begin{tabular}{l|l|l|l|l|l} 
& 1 & 2 & 3 & 4 & 5 \\
$\begin{array}{l}\text { Lecture videos } \\
\text { Online discussion forums } \\
\text { In-class activities } \\
\text { Homework assignments } \\
\text { Textbook } \\
\text { Office hours } \\
\text { Exams } \\
\text { Online quizzes }\end{array}$ & & & & & \\
\end{tabular}


Please rate the extent to which you agree or disagree with the following statements:

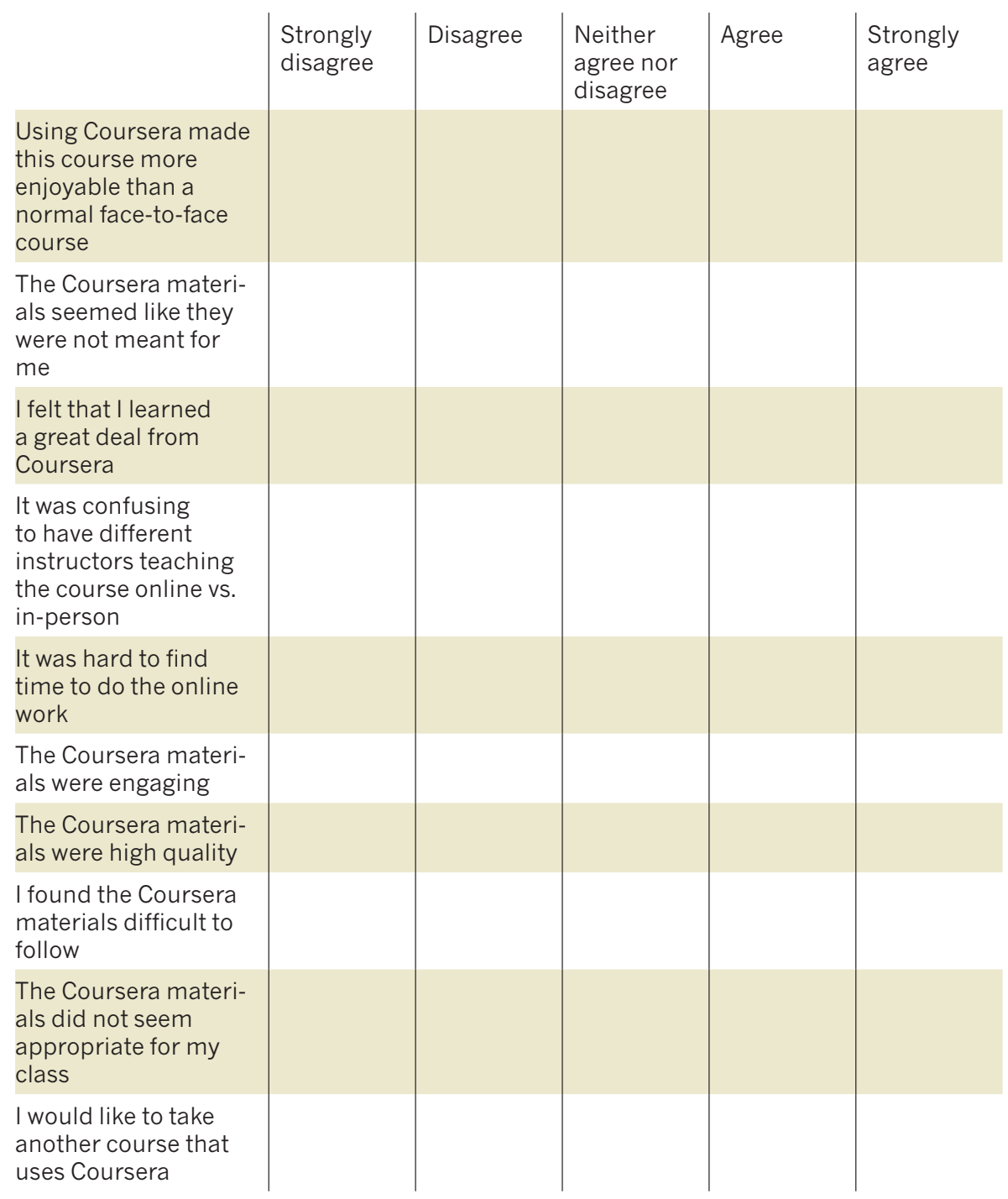

What features of the course do you feel could be improved?

Do you have any other comments you would like to share about [COURSE NAME]? 
In this final section, please provide some information about yourself.

18. What is the highest level of education you expect to complete in the future? Please check one of the following:

Obtain an Associate's degree

Obtain a Bachelor's degree

Obtain a Master's degree or equivalent

Obtain a Ph.D., M.D., or other advanced or professional degree

Don't know

19. How many hours did you work for pay (either on-campus or off-campus) this semester? Please check one of the following:

I did not work

I worked 1-9 hours each week

I worked 10-19 hours each week

I worked 20-29 hours each week

I worked 30-39 hours each week

I worked 40 or more hours each week

20. Where do you live? Please check one of the following:

On-campus housing

I live with parent(s) or other guardian(s)

I live independently (alone, with my own family, or with roommates)

21. Please indicate the highest level of education completed by your

Father (or parent/guardian \#1): $\quad$ Mother (or parent/guardian \#2):

(Please check one of the following.)

Did not complete high school Did not complete high school

High school diploma or equivalent High school diploma or equivalent

Some college Some college

Bachelor's or four-year degree Bachelor's or four-year degree

Graduate or professional degree Graduate or professional degree

Don't know

Don't know

22. Are you married?

Yes

No

23. Do you have children or other dependants?

Yes

No 
24. What is the approximate combined income of your parents before taxes? (Please check one of the following.)

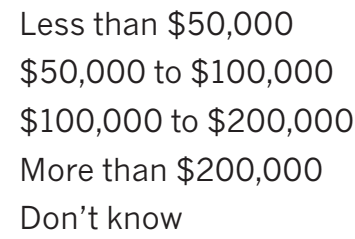

25. What language do you know best? (Please choose one of the following.)

English

English and another language about the same

Another language

* Several questions are adapted from the National Survey of Student Engagement. We have obtained permission from Indiana University to use these questions. 